\begin{tabular}{|l|l|l|l|l|l|}
\hline MUNIBE Antropologia-Arkeologia & $n^{\circ} 69$ & $157-175$ & DONOSTIA & 2018 & ISSN 1132-2217 • elSSN 2172-4555 \\
\hline
\end{tabular}

\title{
Luz para ver y ser vista: los efectos de la iluminación solar durante el solsticio de invierno en los dólmenes de corredor de la provincia de Burgos
}

\author{
Light to see and be seen: the sunlight effects during the winter solstice \\ in the passage graves in the province of Burgos
}

PALABRAS CLAVES: Dolmen, solsticio, megalitismo, arte prehistórico, arqueología, astronomía, arqueoastronomía, Burgos, Norte Península Ibérica GAKO-HITZAK: Trikuharria, solstizioa, megalitismoa, historiaurreko artea, arkeologia, astronomia, arkeoastronomia, Burgos, Iberiar penintsulako iparraldea. KEY WORDS: Dolmen, solstice, megalithism, prehistoric art, archaeology, astronomy, archaeoastronomy, Burgos, Northen Iberian Peninsula.

\section{Rodrigo GIL-MERINO RUBIO(1), Miguel MORENO GALLO(2), Germán DELIBES DE CASTRO(3) y Rodrigo VILLALOBOS GARCíA ${ }^{(3)}$}

\section{RESUMEN}

Presentamos un intento de profundizar en el significado y circunstancias culturales en las que se construyeron los sepulcros de corredor neolíticos del noreste de la Submeseta Norte española, combinando características astronómicas, topográficas y orográficas del terreno circundante. Describimos el trabajo de campo realizado para observar sobre el terreno los efectos de la luz del sol naciente en varios de tales dólmenes, demostrando que las orientaciones fueron minuciosamente calculadas para propiciar que, unos pocos días en torno al comienzo del invierno, los rayos solares se adentraran por el pasillo e iluminaran el interior de los sepulcros y manifestaciones artísticas asociadas que describimos. Por todo ello deducimos la posible existencia de una estructura sociocultural con rituales, ceremonias y actividades funerarias ligadas a un conocimiento profundo del calendario y especialistas dedicados a la planificación y construcción de estos dólmenes y sus espectáculos luminosos ligados a ellos.

\section{LABURPENA}

Espainiako iparraldeko azpimesetako ipar-ekialdeko korridoreko hilobi neolitikoak eraikitzeko garaian oinarri izan ziren gorabehera kulturalak eta esanahia sakontzeko saiakera da honako hau. Horrekin lotuta, inguruko eremuko ezaugarri astronomikoak, topografikoak eta orografikoak uztartu ditugu. Eguzki atera berriaren argiak trikuharri horietan dituen eraginak tokian bertan behatzeko egindako landa-lana deskribatu dugu, orientazioak zehatz-mehatz kalkulatu zituztela erakutsita. Orientazio horien helburua zen neguaren hasiera inguruko egun gutxi batzuetan, eguzki-izpiak korridorean barrura sartzea eta deskribatutako hilobien barnealdea eta haiei lotutako adierazpen artistikoak argiztatzea. Horregatik guztiagatik ondorioztatu dugu egutegiaren ezagutza sakonari lotutako erritualak, zeremoniak eta hileta-jarduerak zein trikuharri horien eta haiei lotutako ikuskizun argidunen plangintza egiteaz eta haiek eraikitzeaz arduratzen ziren espezialistak zituen egitura soziokulturala egon zitekeela..

\section{ABSTRACT}

We here present a tried to deeper understand the meaning and cultural circumstances in which megalithic tombs with corridor where built in the north-east of the northen sub-plateau of the Iberian Peninsula, combining astronomical, topographical and orographic characteristics of the surroundings. We also describe the fieldwork performed to observe on the ground the effects of the dawn sunlight in several of these dolmens, demonstrating that the orientations where carefully calculated to cause, during the days around the beginning of the Winter, the sunlight to ilumminate the inner parts of the tombs and the art manifestations within that we describe. From here we deduce the possible existence of a sociocultural structure with rituals, ceremonies and funerary activities bound to a sound knowledge of the calendar and a specialiazed workforce dedicated to the design and construction of these dolmens and light effects associated to them.

\footnotetext{
(1) r.gilmerino@gmail.com. Dpto.Física Moderna. Avd. de los Castros s/n. Facultad de Ciencias. Universidad de Cantabria

(2) Universidad de Burgos.

(3) Universidad de Valladolid.
} 


\section{INTRODUCCIÓN: ARQUEOASTRONOMÍA Y FENÓMENO DOLMÉNICO}

La Península Ibérica y, en general, la fachada atlántica europea cuentan con un gran número de monumentos megalíticos de época neolítica que fueron utilizados como panteones o sepulcros colectivos. Los primeros estudios sobre el tema se remontan al siglo XVIII y algunos de ellos ya se planteaban relacionar su orientación con fenómenos celestes (Michell, 2002). Desde entonces y sobre todo en el siglo XX se ha consolidado una disciplina, la Arqueoastronomía, que demuestra que los objetos y los acontecimientos celestes fueron muchas veces determinantes en la planificación y construcción no solo de los monumentos megalíticos sino de todo tipo de complejos arqueológicos (p.e. Belmonte, 2000; Hoskin y Allan, 1995; Hoskin, 1997 y 2001; Sweatman y Tsikritsis 2017).

En el caso concreto de las construcciones dolménicas europeas, la bibliografía es muy extensa (Hoskin et al. 1996; Hoskin y Zedda, 1997; Belmonte, 1997; Hoskin y Calado, 1998; Chevalier, 1999; Sauzade, 2000; Hoskin y Higginbottom, 2002; Oliveira et al. 2007; González-García y Costa-Ferrer, 2006 y 2007; González-García et al. 2009; Hoskin, 2009; Belmonte et al. 2013). Y la concerniente a los de España, que se inicia en el siglo XIX (O’Reilly, 1893-96), no le va a la zaga habiéndose publicado en las dos últimas décadas multitud de trabajos, en su mayoría de M. Hoskin, sobre los principales focos megalíticos: Andalucía (Hoskin et al. 1994; 1995 y 2001; Gómez y Hoskin, 2000), Extremadura (Hoskin y Belmonte, 1988; Hoskin y Sauch, 1999), el noroeste peninsular (Hoskin y Palomo, 1998a; López Plaza et al. 1992), las penillanuras salmantinas (López-Plaza et al. 1998), el País Vasco (Vivanco, 1981; Armendáriz, 1996), el Pirineo central y oriental (lund, 2002; Belmonte y González-García, 2012) o Cataluña (Hoskin y Palomo, 1998b; Font-Cot, 2005). Un resumen útil de la evolución de las investigaciones arqueoastronómicas en España es el ofrecido por Cerdeño et al. (2006).

La arqueoastronomía megalítica ha priorizado el estudio de los sepulcros de corredor, sin duda debido a la rotundidad de sus ejes y al carácter pautado de sus orientaciones asociadas a ortos y a ocasos de sol o luna en momentos concretos del año (González-García, 2009). En el norte de la Península Ibérica se observa un predominio, en general, de las orientaciones de los pasillos dolménicos hacia el Este-Sureste o solsticio de invierno, repitiendo el patrón documentado en otras muchas zonas de Europa con declinaciones entre $80^{\circ}$ y $180^{\circ}$ (Scarre, 2008). Pero aún más precisos e ilustrativos son los resultados de un estudio sobre 1.700 dólmenes de España y Francia las cuales denotan una aplastante mayoría de orientaciones a los solsticios de verano e invierno, con solo una leve desviación hacia el tramo comprendido entre los equinoccios y el solsticio de invierno (Hoskin, 2008). En todo caso, conviene recordar que en muchos de los estudios a los que nos referimos no se tuvo en cuenta la variación del azimut del orto solar en los solsticios en función de la latitud, circunstancia que puede suponer variaciones de cierto calado: en el solsticio de invierno el sol sale en Tarifa a $119^{\circ}$, mientras que en La Lora burgalesa lo hace a $122^{\circ}$ y en Carnac, en la Bretaña francesa, a $125^{\circ}$. En el mismo día, el sol aparece en las islas Orcadas nada menos que a $137^{\circ}$ respecto al Norte geográfico

\section{EL FENÓMENO DOLMÉNICO EN LAS LORAS: ASPECTOS GENERALES, PRIMEROS ESTU- DIOS ARQUEOASTRONÓMICOS Y OBJETIVO DEL PRESENTE TRABAJO}

La comarca de Las Loras, que se extiende por el noroeste de la provincia de Burgos y, en menor medida, por el noreste de la de Palencia, es un inmenso altiplano labrado en las calizas del Cretácico, a 1.000-1.100 m.s.n.m (fig. 1). Una dilatada trayectoria investigadora, que arranca con el descubrimiento en 1954 del dolmen de El Moreco y que se prolonga hasta el presente (Moreno, 2005), ha permitido que a día de hoy se conozcan en este espacio alrededor de un centenar de túmulos prehistóricos. La excavación de una docena larga de ellos revela que se trata de monumentos de arquitectura variada -túmulos no ortostáticos, dólmenes simples y grandes sepulcros de corredor- los cuales acogen por lo general inhumaciones colectivas fechados entre c. 4000 y 3300 cal a.C. (Delibes de Castro et al. 1993; Delibes de Castro y Rojo-Guerra, 1997; 2002).

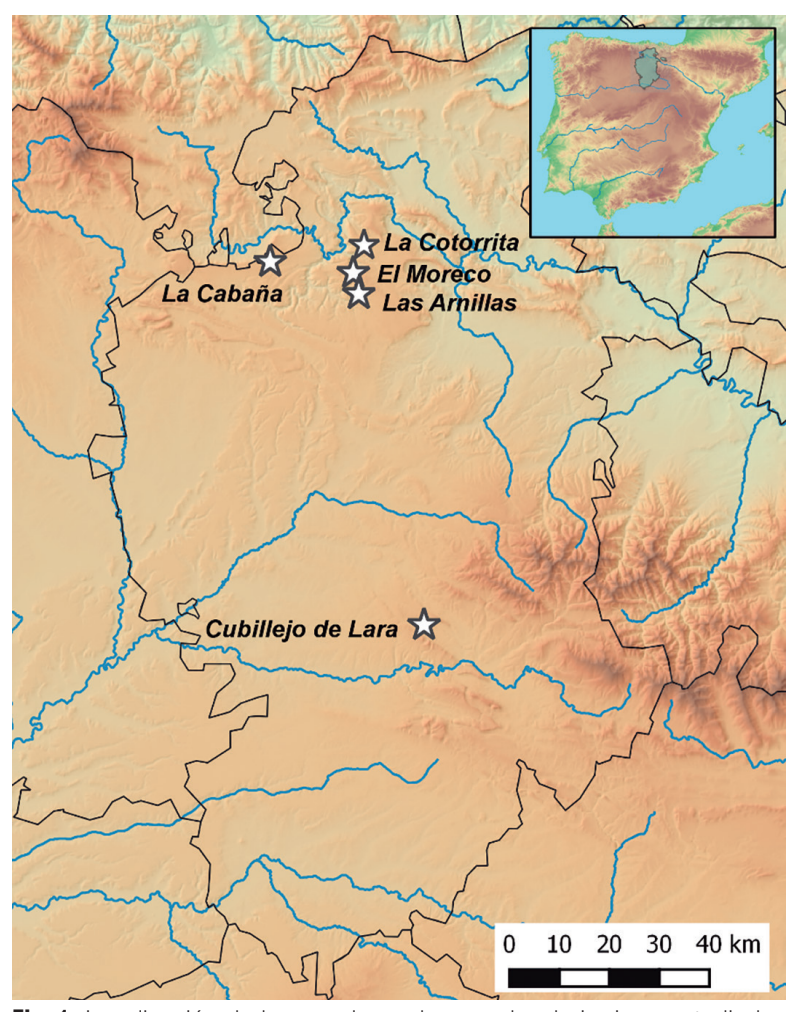

Fig. 1. Localización de los sepulcros de corredor de La Lora estudiados en el presente trabajo / Localization of the passage graves from La Lora studied in this work. 
En el transcurso de las intervenciones se han documentado eventos como la reorganización de algunos de los osarios, la manipulación de huesos humanos o variadas reestructuraciones arquitectónicas, indicativos de que tales lugares no fueron simples tumbas sino espacios donde se desarrollaron ciertas actividades ¿rituales? ¿trascendentales? y que fueron visitados y revisitados con persistencia a lo largo de siglos (Villalobos, 2014). Un análisis de distribución espacial a escala macro revela que estas tumbas monumentales se encuentran en estrecha relación con recursos básicos como fuentes, buenas tierras de cultivo y caminos óptimos, y que a lo largo del IV milenio cal a.C. se habría dado una aparente "escalada simbólica" entre los campesinos loriegos por construir mayores y más visibles monumentos (Villalobos-García et al. 2014). Los pocos yacimientos domésticos de cronología tardoneolítica identificados en la zona -Canalejas, Las Casarinas, La Nava de Rehoyo, Las Pardas- son muy modestos y han ofrecido escasos materiales (Delibes, 2000: 96; Delibes et al. 2011; Basconcillos et al. 2011), aspectos ilustrativos de un poblamiento intermitente e itinerante. Todo ello sugiere que la monumentalidad funeraria loriega se ajusta a esa función de marcador territorial que planteara de forma generalista Renfrew (1976), y que también parece darse en otros focos megalíticos próximos (e.g. Delibes de Castro et al. 1997): Ios grupos de campesinos neolíticos itinerantes habrían reclamado su territorio mediante construcciones costosas y visibles ante la imposibilidad de hacerlo por medio de aldeas estables y permanentes. De esta forma, el megalito no sólo habría sido la tumba de la comunidad sino también, probablemente, el referente simbólico más importante de cara a su interacción con el medio y con otras comunidades.

El primero en referirse al fenómeno astronómico en relación con estos monumentos fue J. Campillo (1984), quien apreció una orientación general de los sepulcros de corredor de la Lora hacia el Sureste y excepcionalmente al Este, de forma similar a los alaveses y catalanes pero tal vez no a los de las penillanuras salmantinas ${ }^{1}$. M. Rojo-Guerra (1993) también acreditó una gran homogeneidad en los rumbos de los corredores sedaneses, entre los $117^{\circ}$ de Ciella y los $143^{\circ}$ de La Cotorrita, con la única excepción del dolmen de Valdemuriel, cuya orientación coincide prácticamente con los $90^{\circ}$. Posteriormente Hoskin (2000) midió las orientaciones de los dólmenes burgaleses, encontrando que el azimut en los de Sedano y Las Loras estaba entre $101^{\circ}$ y $126^{\circ}$ y que el de Cubillejo, más al sur, en la zona de Lara, se orientaba justo a la media de la salida del sol en invierno. Los $214^{\circ}$ del Ruyales del Páramo, sin embargo, se desmarcaban por completo de la pauta, bien por representar un intento de orientación al ocaso solar en el solsticio de invierno, bien, como se ha temido en ocasiones, por las dudas que esta ciclópea cons- trucción suscita como monumento prehistórico (véase Moreno-Gallo et al. 2012: 353). Por último, en un trabajo más reciente (Gil-Merino et al. 2009) se reanalizó la orientación de los dólmenes más representativos, revisando los azimuts y, sobre todo, valorando en el análisis otros parámetros como la elevación del horizonte frente a los monumentos.

Las conclusiones de este último trabajo arrojaron datos compatibles con los de la mayoría de los estudios previos: el rango general de orientación es al naciente solar pero los azimuts no coinciden exactamente. Eso suscita la duda de si los dólmenes fueron construidos con una orientación sólo aproximada al orto del solsticio de invierno o si fue la elevada topografía del entorno, la cual en determinados casos habría pospuesto varios minutos la salida efectiva del sol, el factor que condicionó la variación. A fin de aclararlo, a comienzos del invierno de 2016 decidimos emular la conocida experiencia de O’Kelly en Newgrange (Patrick, 1974; O’Kelly, 1982) observando directamente desde los propios dólmenes y en las fechas críticas los efectos del sol naciente. El presente escrito tiene por objeto dar a conocer los resultados de tales observaciones y también, como exige cualquier estudio arqueoastronómico (Hoskin, 2008), discutir sus posibles implicaciones culturales.

\section{PLANTEAMIENTO Y MÉTODO}

La investigación multidisciplinar exige que cada especialista aporte su propia perspectiva, en nuestro caso la del arqueólogo mirando al suelo y la del astrónomo atendiendo a los acontecimientos celestes y su periodicidad. Tareas tan dispares justifican la desconfianza de muchos arqueólogos sobre la capacidad de la astronomía para contribuir a la explicación de los fenómenos sociales y, a la inversa, las reticencias de los astrónomos para conciliar el relativismo antropológico con la exactitud de los cálculos matemáticos que rigen y explican los fenómenos celestes. Sin embargo, las concepciones cosmológicas del mundo y la vinculación de acontecimientos sociales a efemérides astronómicas están tan generalizados que "si la arqueología pretende investigar la forma en la que las percepciones del mundo afectan a las acciones humanas y a sus representaciones, el cielo no puede ser ignorado" (Ruggles, 2008).

Nuestro trabajo, partícipe de dicha filosofía, repite básicamente el método seguido en investigaciones arqueoastronómicas previas (Gil-Merino et al. 2009) cuyo objetivo fue medir la orientación de los dólmenes con corredores "bien definidos", es decir de solo aquellos con pasillos perfectamente conservados o que, aunque en parte mutilados, mostraran alineación con la entrada de las cámaras. La orientación fue medida respecto al Norte geográfico con una brújula magnética Brunton, fijada

\footnotetext{
${ }^{1}$ Algo en lo que discrepan Delibes de Castro y Santonja (1986) quienes creen que la pauta de orientación en Salamanca es hacia el Sureste.
} 
para mayor estabilidad en un trípode desmagnetizado de la misma marca. Aunque el error de escala de esta brújula es de $1^{\circ}$, la incertidumbre reportada siempre es algo mayor al sumarse a cierta indeterminación en el trazado del eje de los corredores. También se puso buen cuidado en comprobar que en las proximidades de los monumentos no existieran campos magnéticos artificiales -líneas eléctricas, transformadores, dispositivos electrónicos, etc.- ni variaciones del campo magnético terrestre que pudieran falsear las mediciones ${ }^{2}$.

Por otro lado, conscientes de que el orto solar aparente se verá retrasado en aquellos casos en que el horizonte se muestre bloqueado por montañas u otros obstáculos cercanos, además de las orientaciones también consideramos la altura de aquel en la proyección del corredor. Por ejemplo, si el horizonte se eleva 10 grados, la salida del sol se retrasará alrededor de una hora y el azimut a la hora del orto también se desplazará aproximadamente 10 grados (para la latitud del lugar, ver fig. 2 con una descripción matemática sencilla). La orografía del entorno juega, pues, un papel importante en la estimación de los azimuts (Commings y Whittle, 2003), pudiendo darse el caso de que aunque los de varios dólmenes no coincidan por completo, en realidad todos apunten al orto solar alrededor de una fecha determinada, una vez corregido el "efecto horizonte". La altura del horizonte se midió con el clinómetro y los niveles de la misma brújula Brunton.

Si el resultado de aquel trabajo fue reconocer la existencia de un patrón regular en la orientación de los dólmenes hacia la salida del sol de comienzos del invierno, lo que nos planteamos ahora es profundizar en el grado de intencionalidad y en la razón de ser de dichas orientaciones: ¿El corredor está correctamente orientado para que la luz, en la fecha indicada, se

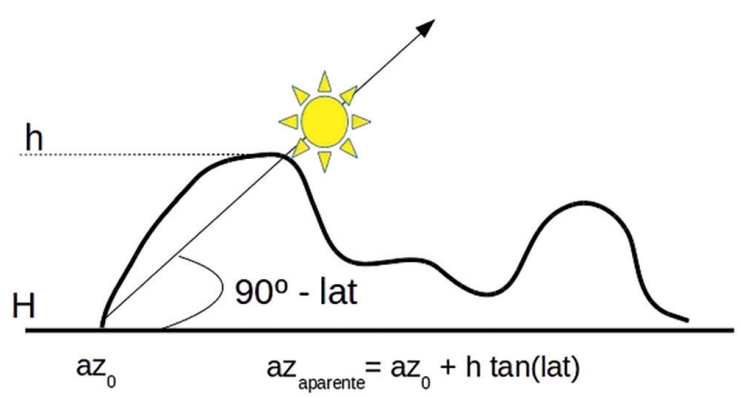

Fig. 2. Para un horizonte plano, el azimut del orto solar es az. Si encontramos un obstáculo de altura h, el nuevo azimut aumenta en una cantidad resultante del producto de la altura angular del obstáculo por la tangente de la latitud del lugar / For a flat horizon the sunrise azimuth is $a z$. If one finds a obstacle of height $h$, the new azimuth increases in an amount resulting from the product of the angular height of the obstacle times the tangent of the latitude of the site. adentre por el pasillo y acierte a iluminar el interior de la cámara? ¿Cuánto tiempo dura el fenómeno cada día? ¿Durante cuántos días alrededor del solsticio? ¿Era el ortostato opuesto al corredor, la losa que se denomina de cabecera, el más iluminado y por tanto el objetivo de esta iluminación? ¿Estuvo la posición de ciertas grafías -grabados y pinturas- en lugares muy concretos del interior de los monumentos supeditada al recorrido de la luz solar?

La observación sobre el terreno de la incidencia solar estará en condiciones de dar respuesta a estas preguntas, siempre que asumamos que la imagen cósmica actualmente observable desde el megalito es la misma a la que tuvo acceso el hombre prehistórico. Ello exige una reflexión sobre el concepto de azimut y una breve explicación de cómo nos movemos en el espacio estelar y de cómo lo hacen los astros más cercanos. En una situación "ideal" en la que la Tierra fuera un sólido esférico, su órbita alrededor del sol un círculo perfecto y su movimiento de rotación únicamente alrededor de su eje, el cálculo de efemérides celestes sería mucho más sencillo de lo que realmente es. Pero la Tierra tiene una órbita elíptica alrededor del sol cuyo plano forma actualmente un ángulo de $23,5^{\circ}$ respecto al ecuador terrestre, lo que da lugar a la existencia de las estaciones, que no tienen una duración igual precisamente por la elipticidad de la órbita, ya que la Tierra en su movimiento debe barrer áreas iguales en tiempos iguales. La intersección de la órbita terrestre con su plano ecuatorial da lugar a dos puntos, el "primer punto Aries o vernal" y el "primer punto Libra", que cuando el sol se encuentra en ellos marcan los equinoccios de primavera y otoño, respectivamente. El punto Aries es también el origen del sistema de coordenadas ecuatoriales, que utilizamos para situar astros en el firmamento mediante su declinación y ascensión recta (ver, por ejemplo, Martín-Asín 1990). Este sistema puede convertirse a coordenadas horizontales, que usan la altura angular sobre el horizonte y el azimut o distancia de la perpendicular al horizonte que pasa por el astro con un punto cardinal, que puede elegirse arbitrariamente. En nuestro caso referimos el azimut al punto Norte.

Por otro lado, la Tierra en su rotación se comporta de manera similar a una peonza, con tres movimientos principales: uno alrededor del eje y otro del propio eje, movimiento este último que puede subdividirse en dos, uno de bamboleo y otro de oscilación respecto a dicho bamboleo. El movimiento alrededor del eje provoca la oscilación día-noche y sufre variaciones como consecuencia de las mareas. El bamboleo del eje se denomina precesión y tiene un periodo de unos 26.000 años. En último lugar, la oscilación de la precesión se denomina nutación, con unos 1.300 ciclos en cada periodo de

\footnotetext{
${ }^{2}$ Las mediciones se asimilan perfectamente a las de las ortofotografías del Instituto Geográfico Nacional o a las obtenidas a través del programa informático Sunearthtools (https://www.sunearthtools.com. consultado el 1.10.2017).
} 
precesión, es decir, con un periodo muy pequeño. La nutación puede despreciarse en la mayor parte de los problemas de determinación de coordenadas y de su variación. Sin embargo, la precesión es responsable de que el plano del ecuador se desplace y con él el punto Aries. Por tanto, las coordenadas ecuatoriales y horarias de los objetos astronómicos que tienen su origen en ese punto cambian a lo largo del tiempo, con lo que los azimuts de ortos y ocasos también lo hacen. He ahí la razón de que a este movimiento se le conozca como precesión de los equinoccios, ya que el paso del sol por el punto Aries marca el equinoccio de primavera. Todo lo cual significa que para una fecha determinada las coordenadas de una estrella varían con el paso de los siglos. Así se explica que el Norte se asocie a estrellas diferentes a lo largo del tiempo (Herrmann, 1987): si hace unos 5.000 años, en la época de construcción de algunos monumentos megalíticos europeos, Thuban (a-Draconis) señalaba el Norte, dentro de unos 13.000 años lo será Vega (a-Lyrae) de nuevo, ya que también lo fue en esa cantidad de años antes de Cristo (jrecordemos el periodo de precesión terrestre!).

Como acabamos de ver, el movimiento de precesión de los equinoccios afecta a las coordenadas de las estrellas modificando, cuando se trata de periodos del orden de siglos, los tiempos en los que ocurren sus ortos y ocasos. Sin embargo, esto no sucede en el caso de la luna y del sol. Las coordenadas de la luna varían por la precesión de su propia órbita, que tiene un periodo de 18,6 años. Las del sol, por su parte, varían debido a la precesión planetaria, el efecto gravitatorio conjunto de todos los planetas del Sistema Solar, la cual afecta también a la órbita terrestre disminuyendo la inclinación de la eclíptica a razón de casi -0,5" por año. Esto significa que, si bien una alineación de estrellas con una determinada construcción terrestre dejaría de existir al cabo de unos pocos siglos, se necesitaría un periodo mucho más largo de tiempo para perder alineaciones respecto al sol. En concreto, para una latitud como la de Las Loras, el orto y el ocaso solar para una fecha determinada del año sufren una variación de unos 15" en 2.000 años (ver, por ejemplo, Belmonte 2000). Esto significa que la desviación entre el Neolítico y el presente no llega a $1^{\circ}$. En la figura adjunta, elaborada sirviéndonos de Meeus (1991), se representa la variación del azimut solar al amanecer del solsticio de invierno en Las Loras para comprender mejor el fenómeno y su poca repercusión en la planificación de nuestro trabajo de campo (fig. 3).

Por tanto, si existió en origen una intencionalidad en la construcción de los dólmenes de Las Loras respecto a su orientación solar, podemos estar seguros de que acudiendo a los lugares señalados en fechas próximas al solsticio de invierno veremos lo mismo que los arquitectos que planearon los mismos sepulcros hace 6.000 años. Para dotar de mayor capacidad predictiva a nuestro trabajo de campo, decidimos hacer una simulación de la iluminación solar sobre un esque-

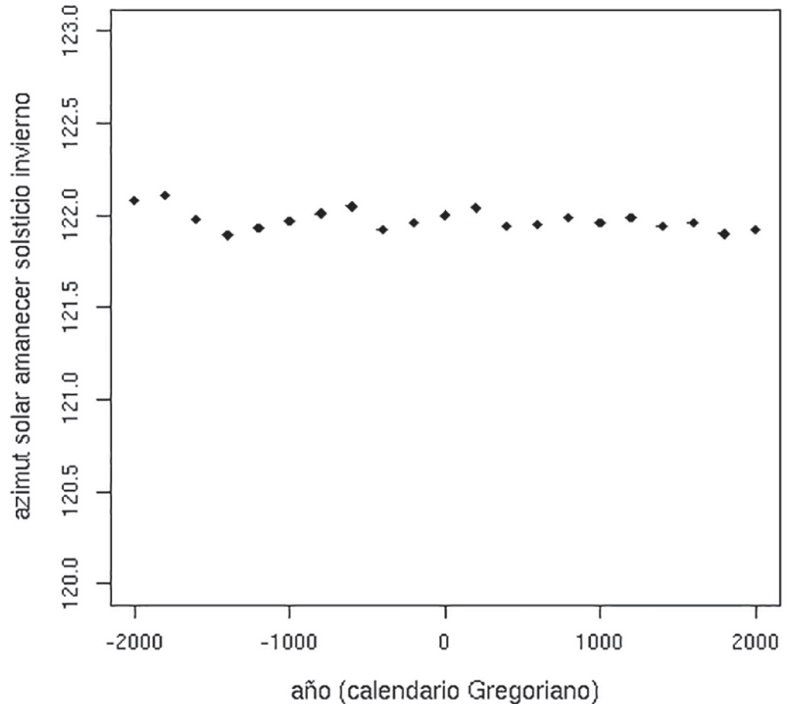

Fig. 3. La variación de las coordenadas solares para una determinada fecha del año en latitudes como la de Las Loras no sufre una variación significativa en los periodos de estudio y con los objetivos propuestos (ver texto para más detalles) / The variation of the solar coordinates for a given date in the year in latitudes close to Las Loras do not suffer a significant variation during the periods of study and for the objectives of this study (see text for more details)

ma de un típico sepulcro de corredor, orientado a unos $121^{\circ}$ norte y suponiendo el día de observación en el solsticio de invierno. Nuestra pequeña simulación dio como resultado que durante un periodo de tiempo al salir el sol la cámara estaría iluminada (fig. 4).

Con tales presupuestos afrontamos el trabajo de campo. Entre el 31 de diciembre de 2016 y el 25 de enero de 2017 se acudió de madrugada a tres de los dólmenes más significativos de la zona de Las Loras, en los páramos del noroeste de la provincia de Burgos: El Moreco en Huidobro, Las Arnillas en Moradillo de Sedano y La Cabaña en Sargentes de la Lora. La

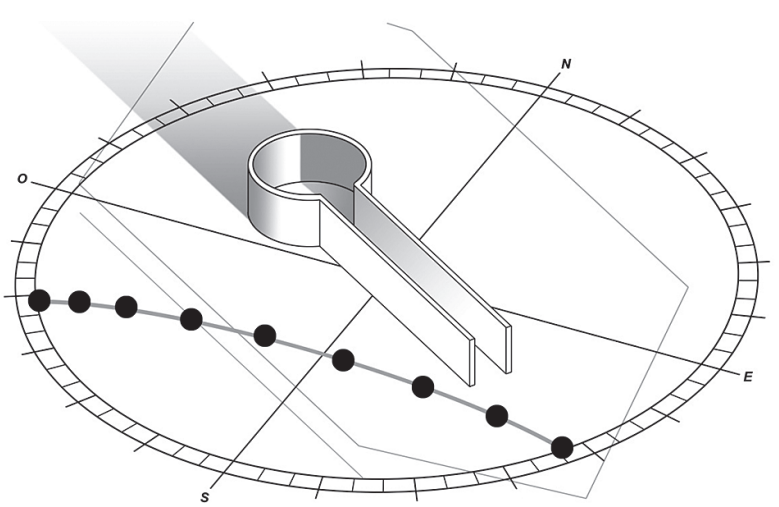

Fig. 4. Modelo de dolmen de corredor orientado al orto solar del solsticio de invierno. La trayectoria del sol (círculos negros) permite comprobar cómo éste únicamente alcanzaría a iluminar el interior de la cámara al amanecer / A model of a passage grave oriented to the sunset at the Winter solstice. The path covered by the sun (black circles) allows us to determine the illumination of the inner part of the tomb chamber at dawn. 
elección tuvo en cuenta la monumentalidad pero sobre todo, como dijimos, el buen estado de conservación de las construcciones, descartándose otros sepulcros de corredor, como La Nava Negra, que presentaban pasillos de acceso arruinados e invadidos por la vegetación, o como Fuente Pecina 1, cuya estructura fue reenterrada en su día velando por su conservación. Igualmente, considerando la singularidad de su azimut, incorporamos a la muestra La Cotorrita, en Porquera de Butrón, y otro tanto acabamos haciendo con el dolmen de Cubillejo de Lara o Mecerreyes, más de $50 \mathrm{~km}$ al sur de las parameras loriegas pero con un diseño arquitectónico idéntico al de los sepulcros de esta zona. En cualquier caso, los problemas para la observación no fueron menores: nieblas y nubes son frecuentes, habituales en el invierno de la Meseta Norte, o, lo que es lo mismo, madrugar no garantiza la limpieza del cielo en el amanecer. Esto sucede incluso en los días anticiclónicos, pues no es infrecuente que en ese momento se produzca un proceso de cambio de gradiente térmico y que la niebla ascienda del valle para terminar cubriendo el cielo justo unos minutos antes de que salga el sol. Cuando el cielo está despejado, a esas horas de la madrugada, hacia las 8:00 am hora solar, las temperaturas suelen ser inferiores a $-10^{\circ}$ Celsius (fig. 5).
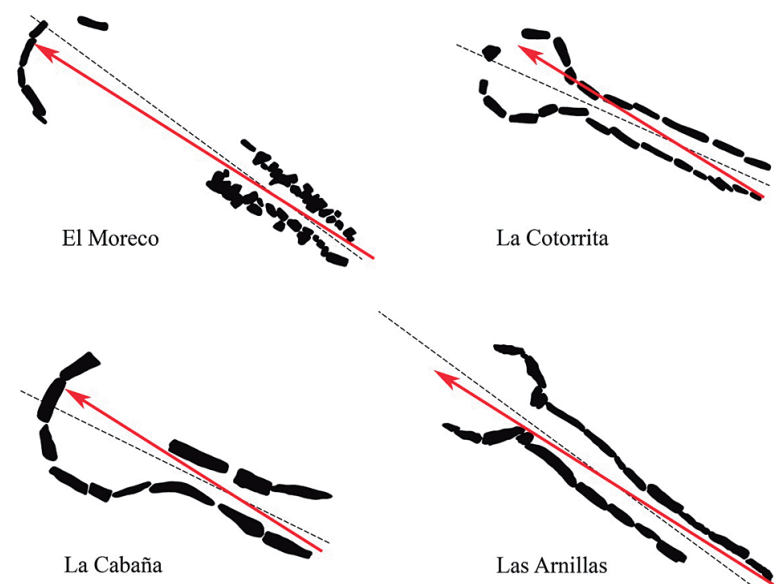

La Cotorrita
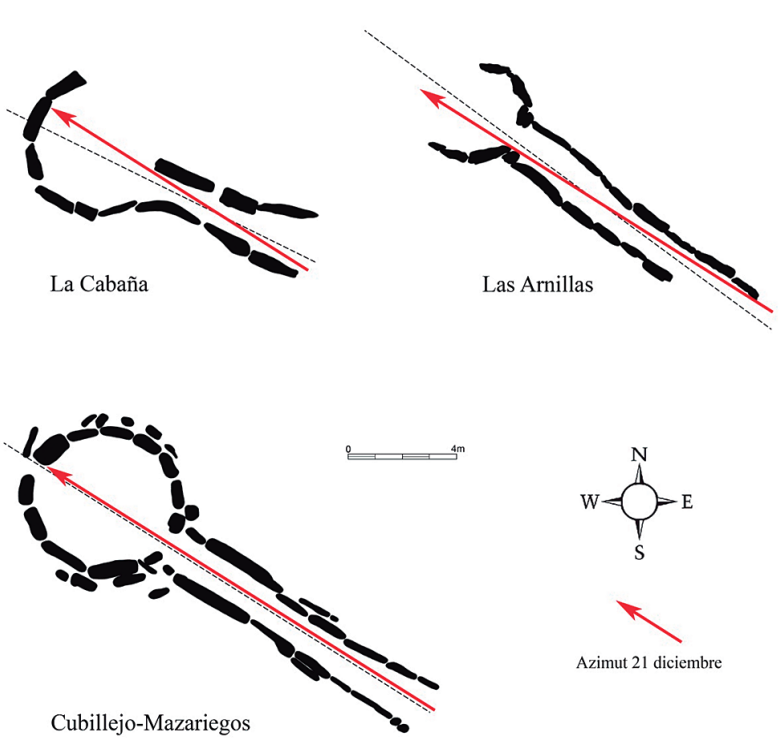

Fig. 5. Plantas de los sepulcros de corredor burgaleses estudiados. Nótese la falta de coincidencia entre sus ejes de simetría (línea de puntos) y de la proyección del sol naciente en el solsticio invernal (vectores grises) / Plans of the passage grave from Burgos studied here. Note the lack of superposition between the simetry axis (dot line) and the projection of the rising sun at the Winter solstice (grey vectors).

\section{RESULTADOS DE LA OBSERVACIÓN}

a) El Moreco (Huidobro-Los Altos): Es sepulcro de corredor de amplia cámara (4 m de diámetro) y largo pasillo (10,5 m), que ofrece la particularidad de presentar figuras pintadas en rojo, entre ellas un antropomorfo esquemático, sobre algunas de las lajas camerales (Delibes y Rojo, 1989). Dos circunstancias dificultan aquí la percepción del efecto solar: la abundancia de matorrales en el corredor, motivada por el abandono del monumento tras su restauración (Delibes de Castro, 2000), y la existencia de un rodal de pinos de repoblación justo en la línea del sol naciente. Ambas obstaculizan la proyección de la luz del amanecer sobre el megalito, como comprobamos el 31 de diciembre de 2016. Además, el horizonte coincide en el orto solar con una loma, el Alto del Cerro, por lo que la salida real para alumbrar el dolmen se produce 30 minutos después de que comience a iluminarse el espolón de Peña Otero (1.205 m.s.n.m., 140 metros más elevado que el dolmen), situado justo a espaldas del corredor. Pese a todo, la observación en El Moreco es agradecida, porque siquiera durante media hora la vegetación no impide apreciar el fenómeno del sol avanzando por el corredor e incidiendo en el fondo del hipogeo. Hecho a destacar, por su posible influencia en la iluminación actual, es que en este monumento se han restituido modernamente los dinteles del extremo proximal del corredor, de acuerdo con el modelo acreditado en los dólmenes de La Cabaña y Las Arnillas.

Se constata en El Moreco, igual que en otros dólmenes de la zona, una desviación del eje del corredor respecto al de la cámara -lo cual podría ser una característica generalizada a explorar en otro trabajo. Son solo $2^{\circ}$ o $3^{\circ}$, pero los suficientes para que la luz que penetra por el pasillo no se proyecte directamente en la losa de cabecera, sino en su inmediata hacia el Norte. El fenómeno es especialmente importante porque la primera de tales losas presenta la pintura antropomorfa de más entidad que, en buena lógica, debería haber sido el objetivo principal de la iluminación: ¿un fallo de planeamiento? ¿una modificación arquitectónica posterior?

b) La Cabaña (Sargentes de la Lora): Se trata de otro de los mayores dólmenes de la zona, con una cámara casi circular de 3,2 m de diámetro y un pasillo de $6 \mathrm{~m}$ de largo y seguramente mutilado en su extremo distal. El corredor conserva aún en el tramo opuesto dos grandes dinteles originales y ofrece, además, la particularidad de ir ensanchándose progresivamente conforme se proyecta hacia el exterior (Delibes de Castro et al. 1993). Al ser megalito perfectamente conservado, gracias a los cuidados que recibe del Ayuntamiento de Sargentes, la observación astronómica pudo realizarse en condiciones óptimas.

También aquí la salida del sol se ve taponada en el orto invernal por un promontorio, Cuesta Rebolleda, que retrasa varios minutos la irradiación solar en su interior. Pero una vez comienza el fenómeno, éste se pro- 
longa durante más de dos horas. Como en el resto de los casos observados, el rayo de luz ilumina primero las losas de cabecera y va descendiendo en diagonal hasta incidir en los ortostatos más orientales del corredor. Lógicamente, este recorrido se corresponde, de forma inversa, con el que efectúa el sol visto desde dentro de la cámara, puesto que sale en el horizonte y se desplaza, a ojos del observador, en una diagonal creciente a la derecha. Si nos hemos referido a la iluminación de "las" losas de cabecera, y no de "la" losa en singular, es porque también en La Cabaña existe un leve desvío del eje del corredor respecto al de la cámara, nuevamente hacia el Este. No obstante, en la fecha de observación, el 6 de enero, la única laja iluminada es, de las dos, la que adopta una posición más central. Durante los primeros 40 minutos, los rayos del sol llegaron a ella y al suelo de la cámara, y durante otros 80 minutos iluminaron solo el suelo hasta terminar desplazándose el foco a la pared oriental del corredor.

c) Las Arnillas (Moradillo de Sedano-Valle de Sedano): Es el más monumental y el mejor conservado de los dólmenes burgaleses y consta de una cámara poligonal de tendencia circular (4 $\mathrm{m}$ de diámetro) y de un corredor (12 m) que en el extremo proximal aún conserva tres dinteles de la cubierta primitiva (Delibes de Castro et al. 1986). La observación se llevó a cabo en él el 8 de enero, y como se encuentra en un punto culminante de la paramera, no hay ningún relieve o accidente que se interponga con el sol naciente. Sin embargo, el fenómeno dura poco más de una hora en esa fecha.

Comienza también en el extremo inferior del ortostato de cabecera ${ }^{3}$ y casi media hora después ilumina únicamente el suelo de la cámara, prolongándose el fenómeno durante 40 minutos. Como es lógico, el eje de los rayos del sol termina por proyectarse sobre la pared oriental del dolmen, y entonces tiene lugar un auténtico espectáculo visual al resaltar la luz rasante el relieve de dos losas calizas contiguas que se localizan en el corredor y que presentan series de "rizaduras" paralelas. Otra cuestión observada es la forma del corredor visto desde el interior de la cámara. En las fotografías se advierte que el perfil de la "ventana" de luz es similar a un trapecio invertido. Las paredes del corredor tienen un tamaño decreciente desde el centro hacia la periferia, e inversamente se ve desde dentro un cuadrángulo más ancho en su parte superior. Este hecho permite que el recorrido del sol sea más largo respecto a la proyección, porque seguirá iluminando hasta el final la unión de la pared occidental del corredor con el dintel correspondiente. Es probable que semejante geometría luminosa sea resultado de una concienzuda planificación.

d) La Cotorrita (Porquera de Butrón-Los Altos). Excavado en 1970, el dolmen presenta cámara poligonal de 2,80 $\mathrm{m}$ de anchura y pasillo de 7,5 m de largo (Osaba et al. 1971a), y, a pesar de que no existen obstáculos en el horizonte que taponen la primera luz solar, tiene el corredor orientado más al este de lo común y de lo que correspondería si la pretensión era alinearlo con el orto de invierno. Así, frente a los $126^{\circ}$ de azimut de El Moreco y de Las Arnillas, o los $121^{\circ}$ de La Cabaña, La Cotorrita tiene $113^{\circ}$. Por lo tanto, teóricamente el eje debería corresponder con la salida del sol a finales del mes de enero. La visita se hizo el día 20 de ese mes, con una suerte relativa porque la presencia de nubes en el horizonte retrasó la proyección solar y únicamente permitió observar el fenómeno durante algunos minutos hasta que de nuevo las nubes cubrieron el cielo. El eje del corredor, una vez más, no está perfectamente alineado con el de la cámara y de hecho la proyección se produce entre dos losas de cabecera, al menos en la fecha de observación. Esta ligera falta de correspondencia entre la orientación de corredores y cámaras no puede atribuirse a modificaciones sufridas por los monumentos durante el proceso de restauración pues figura incluso en algunas planimetrías originales, realizadas antes de las excavaciones.

e) Cubillejo de Lara (Mecerreyes): El escenario de la última observación fue el dolmen mal denominado de Cubillejo, porque no se localiza en dicha pedanía sino en el despoblado de Mazariegos, del municipio de Mecerreyes. En todo caso, un megalito ajeno a Las Loras y emplazado, a diferencia de los sedaneses, no en sitio dominante sino en una leve depresión de la comarca de Lara de los Infantes. Se trata de un espléndido sepulcro de corredor, de muy amplia cámara circular (6,5 m de diámetro) y largo pasillo (10,5 m), cuyo particular esquema constructivo, con grandes peristalitos, se inspira en los sepulcros megalíticos portugueses de la comarca de la Beira (Osaba et al.1971b; Delibes y Rojo, 1988).

El corredor se sitúa a $128^{\circ}$ de azimut, es decir, algo más al sur que la salida del sol en el solsticio de invierno. Por ello, aunque fue visitado en la tardía fecha del 25 de enero, permitió observar el fenómeno de la iluminación durante casi dos horas, concretamente 103 minutos. Tampoco tiene obstáculos en el horizonte, por lo que el sol naciente incide pronto sobre la mitad inferior de la losa de cabecera. Progresivamente el foco de luz se va desplazando por la cámara hacia el tramo proximal de la pared Este del corredor, y termina iluminando allí una bien conocida losa decorada con grabados esquemáticos (dos cuadrúpedos, un ramiforme y un sol), por desgracia muy erosionados (Ledo-Fernández, 2016). Aunque el efecto de la iluminación en el interior de la cámara no sea aquí tan impactante como en Las Arnillas, porque, a falta de cubiertas en el pasillo, no se

\footnotetext{
${ }^{3}$ En realidad, es ortostato restituido modernamente pero ocupa la posición exacta y reproduce la misma anchura del original, de acuerdo con los datos obtenidos en la excavación de la fosa que en su día lo acogió (Delibes de Castro et al. 1993).
} 
pasa brusca o instantáneamente de la oscuridad a la luz, es destacable que también en Cubillejo el ortostato distinguido con motivos simbólicos se encuentre en la pared oriental del pasillo, esto es allí donde el sol concluye su recorrido.

\section{DISCUSIÓN: ARQUITECTURAS PROYECTA- DAS PARA CONTEMPLAR LA PRIMERA LUZ SO- LAR A COMIENZOS DE INVIERNO}

La observación del fenómeno de la luz del solsticio de invierno, iluminando cada año las entrañas de todos nuestros dólmenes, suscita una serie de reflexiones inevitablemente asociadas a la idea de que quienes los erigieron conocían la mecánica celeste -por ejemplo, la duración del año solar- y la tuvieron muy presente a la hora de orientar sus monumentos funerarios. Pero la reflexión también se extiende, como podremos a ver, a las razones simbólicas que habrían aconsejado a sus constructores y usuarios a actuar de esa manera, e incluso a la explicación de determinados detalles arquitectónicos y decorativos de los monumentos.

5.1. Los azimuts de nuestros sepulcros de corredor, salvo en La Cotorrita, se agrupan entre los $121 \mathrm{y}$ los $128^{\circ}$, mostrando una incontestable pauta de orientación al orto solar del solsticio invernal. Es la misma tendencia que denotan la mayoría de los dólmenes de las regiones occidentales de la Península Ibérica pero no, por ejemplo, los megalitos del Sudeste español o los del Midi francés (Hoskin, 2008), lo que supone respaldo a las teorías clásicas de J. Maluquer de Motes (1973) y H. N. Savory (1974) defensoras de que los monumentos burgaleses y riojanos se inspiraron y participaron de las mismas soluciones constructivas que los del foco dolménico del oeste peninsular. Asimismo es destacable que la totalidad de los dólmenes se orientan a fenómenos celestes y ninguno hacia la Peña Otero, única prominencia de entidad en esta zona de la paramera. Esto restaría fuerza a la hipótesis de que dicho relieve, majestuoso faro en el sector oriental de Las Loras, pudiera haber sido un referente ¿sagrado? como se reivindica, por ejemplo, en el caso del dolmen de Menga y la Peña de los Enamorados de Antequera (Hoskin, 2001).

5.2. En El Moreco y La Cabaña la presencia de sendas lomas frente a los dólmenes determina que el sol salga con cierto retraso respecto al orto teórico de un modelo plano, lo que justifica la pequeña variación hacia el sur del azimut de los corredores: sin duda no es algo fortuito, sino deliberado. En Cubillejo y sobre todo en Las Arnillas, por el contrario, se registra frente al corredor un horizonte lejano, perfectamente horizontal, sin relieves o accidentes orográficos que retrasen la iluminación. Más difícil de interpretar es la problemática de La Cotorrita, situado en un lugar dominante del terreno, pero que presenta un corredor orientado de forma clara hacia el Este, alejado del azimut típico del solsticio invernal. ¿Pudo deberse a la presencia de un tapón arbóreo en sus proximidades, como el que actualmente existe junto al dolmen de Valdemuriel, en Tubilla del Agua?

5.3. Además, la orientación de los monumentos hacia el amanecer del solsticio hiemal es lo bastante precisa para deducir que los proyectistas conocían exactamente la duración del ciclo solar y para justificar la sospecha de que la construcción -o, al menos, la planificación in situ de la misma- se llevó a cabo en el inicio del invierno. Porque ¿cómo saber en cualquier otra estación del año a qué lugar del horizonte debía apuntar el corredor? Todo hace pensar en el reconocimiento hacia el 21 de diciembre por parte de las comunidades megalíticas de un "día sagrado" en el que, entre otras celebraciones, se trazara sobre el terreno la planta de la sepultura o directamente se colocaran las primeras piedras orientadas al orto del sol. Con indudable optimismo, Hoskin (2008) comenta a este respecto que un estudio detallado de las pequeñas variaciones del azimut de los dólmenes alentejanos seguramente permitiría determinar en qué semana exacta del año se construyó cada uno de ellos. En nuestros sepulcros, las pequeñas desviaciones ya comentadas en los ejes de cámaras y pasillos dificultarían lecturas de este tipo, pero además, como hemos subrayado, también habría que tener en cuenta ese "efecto horizonte" motivado por la existencia de accidentes puntuales que bloquean y retrasan la proyección de la luz del orto obligando a corregir los azimuts.

5.4. En La Cabaña y en El Moreco existen leves diferencias en la orientación de cámara y corredor, o, dicho de otro modo, estos no comparten completamente eje de simetría (fig. 5). La consecuencia es que la luz que penetra por el pasillo no se proyecta exactamente sobre la losa de cabecera de la cámara, lo que en El Moreco deja sin iluminar las grafías esquemáticas (Delibes de Castro y Rojo-Guerra, 1989) pintadas en ella. Puede tratarse solo de un error de planteamiento, pero caben otras posibilidades: ¿Tal vez la desviación es fruto de una corrección del eje del pasillo en el último momento de la construcción para adaptarle mejor a la trayectoria de los rayos solares en el orto de invierno? ¿No podría ocurrir que la planificación y construcción de estos sepulcros de corredor se desarrollase en dos fases independientes, una para la cámara y otra para el pasillo, como parece ocurrir en otros dólmenes del norte peninsular (Delibes de Castro y Santonja 1986; Tejedor 2014)? Se trata de preguntas de momento sin respuesta pero que abren nuevas perspectivas a la investigación y que nos llevan a recordar un interesante detalle constructivo de El Moreco: en el corte realizado para conocer la estructura de su masa tumular, se apreció la existencia a distinta altura de dos horizontes de suelo diferentes, como si el megalito en un determinado momento de su trayectoria hubiera sido retumulizado (fig. 6). El detalle es importante porque revelaría dos momentos constructivos, pudiendo ser que el último, en línea con lo planteado más arriba, correspon- 


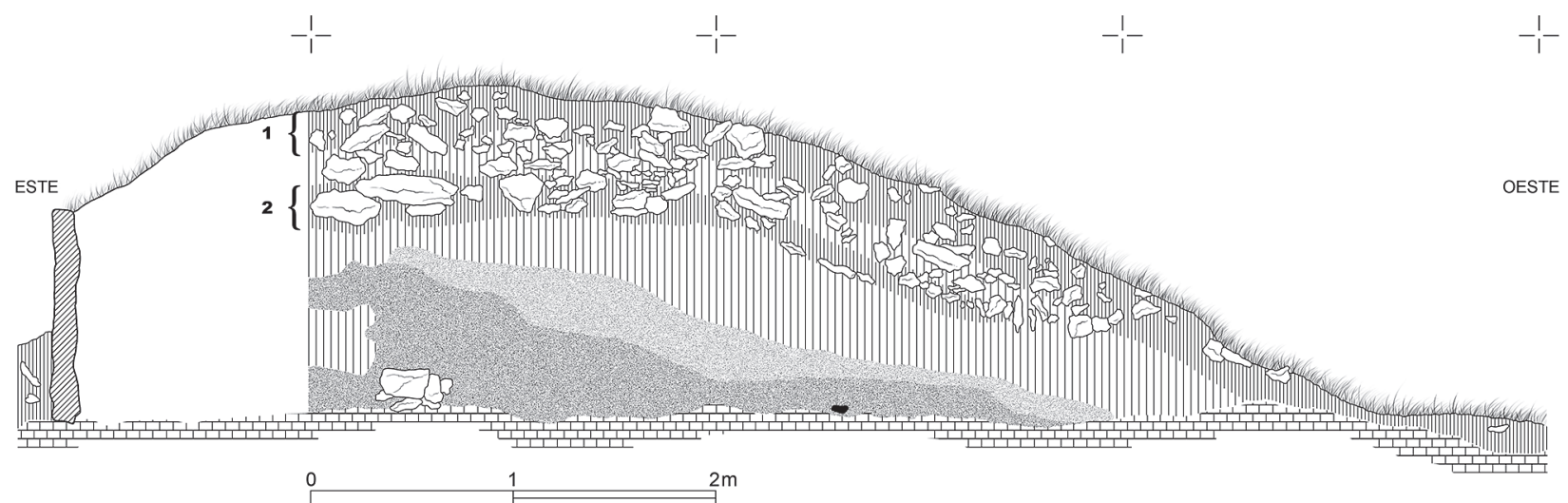

Fig. 6. Posible retumulización de El Moreco, a la vista del reconocimiento de sendos niveles de suelo (1 y 2) superpuestos (a partir de Rojo Guerra (1993) / Possible re-moundering of El Moreco, considering the two ground levels (1 and 2) overlapped (from Rojo Guerra, 1993).

diera precisamente a las obras para dotar de corredor a una cámara preexistente ${ }^{4}$.

5.5. La irrupción de los rayos del sol por el pasillo disipando las tinieblas de la cámara sigue constituyendo en el siglo XXI un espectáculo emocionante, capaz de inspirar músicas tan evocadoras como el Solsticed'hiver a Gavrinis de Thierry Dedieu. Pero lo verdaderamente importante es que no se trata de un espectáculo espontáneo, sino fruto de la creación de un escenario ad hoc en el que el hombre prehistórico empeñó sus saberes astronómicos y edilicios. Todo ello revela el profundo significado que dicho fenómeno debía tener para las comunidades megalíticas al tiempo que invita a pensar que el solsticio hubo de ser para ellas una fecha especial y muy esperada en la que, en un ambiente de celebración colectiva -porque "las cosas sagradas son cosas sociales" y como tales exigen "rituales solemnes o públicos" (Hubert y Mauss, 1889)-, se abría el corredor (fuera de esos días su extremo seguramente permaneciera bloqueado) para observar cómo la luz del sol naciente progresaba hacia la cripta contenedora del osario. ¿Y qué se celebraba? Como en tantas sociedades primitivas, la expiración de los días cortos y fríos del final del año, cuando las noches son eternas, y el inicio de un tiempo nuevo en el que el sol, adelantando su salida y retrasando el ocaso, brindaba una nueva oportunidad al ciclo de la vida ${ }^{5}$.

5.6. Pero la luz, al penetrar en el dolmen y aparte de propiciar el espectáculo, también alumbraba y permitía ver. Una posible ventaja de entrar sin antorchas, solo iluminados por los rayos del sol, es que así se evitaba el peligro de incendio en unos dólmenes que, recordemos, cubrirían sus cámaras con una techumbre vegetal (Delibes de Castro, 2007). Pero si esa hubiera sido la única o la principal razón, habría que suponer que los enterramientos solo tenían lugar en torno al solsticio, obligando a considerar que los cuerpos de los individuos fallecidos a lo largo del resto del año se acumulaban en otro lugar diferente, a la espera de su depósito en las fechas sagradas. El razonamiento nos transporta a un debate clásico del megalitismo: ¿fueron los dólmenes tumbas primarias, donde se enterraban los cuerpos de los difuntos todavía frescos y completos, con los huesos en perfecto orden anatómico, o sólo llegaban a ellos restos parciales descoyuntados, después de haberse perdido los tejidos blandos y los huesos menores en un expositor o pudridero (Masset, 1993)?

La segunda opción, evidentemente, tiene el interés de ser compatible con la teoría de que sólo se enterraba aquellos días en que la cámara permanecía iluminada por el sol, pero el estudio de los osarios de los dólmenes burgaleses no es muy revelador sobre si prevaleció o no el modelo de enterramiento en dos tiempos. Desde luego en ninguno de los monumentos se han documentado esqueletos completos, atribuibles sin discusión a inhumaciones directas, pero en el osario de Las Arnillas sí están presentes la totalidad de las piezas esqueléticas, inclusive aquellos huese-

\footnotetext{
${ }^{4}$ La observación se debe al malogrado geólogo Manuel Hoyos y figura en las notas de sus cuadernos de campo.

5 Es casi un tópico en la bibliografía sobre megalitos relacionar su orientación al este con la de las primitivas iglesias cristianas, pero apenas se repara en el porqué, que no es otro que la identificación de Cristo (la vida) con el sol. Un Cristo al que en la vieja liturgia anterior a Gregorio Magno se denomina "Jesús astro naciente" y del que se dice que viene de arriba para someter al Príncipe de las Tinieblas (Jungmann, 1962). He ahí, pues, materializada en la Navidad, una reminiscencia de las viejas fiestas del solsticio de invierno, pero no la única: en época del emperador Aureliano, en el siglo III, también se rendía culto el 25 de diciembre al Sol invictus, celebrando la marcha ascendente del astro en el inicio del nuevo año (Bonnefoy, 1998). En definitiva, como señalan sugestivamente Bueno, Balbín y Barroso (2008), en los megalitos el sol penetrando desde el este y discurriendo por el pasillo simbolizaba la regeneración de la vida y la victoria de la luz sobre la oscuridad y la muerte, siempre situadas a poniente. Pero también podía entenderse que la llama solar contribuía a mantener vivo el espíritu benefactor de los antepasados enterrados en el monumento, e inclusive, de acuerdo con la interpretación que como gigantesco útero hace Prendergast (2012) del sepulcro de Newgrange, que la luz fuera la simiente de una fecundación cósmica anunciadora o, mejor, convocadora de tiempos mejores para la agricultura y la ganadería.
} 
cillos menores que presentan conexiones más lábiles y que razonablemente podrían haberse desprendido en el pudridero (por ejemplo los de pies y manos), lo que operaría a favor de la hipótesis del enterramiento primario (Delibes de Castro, 1995). El futuro, a través de un mejor estudio de los osarios, tiene la palabra en este asunto, pero de momento la Arqueoastronomía se revela como un inesperado aliado para formular nuevas preguntas.

5.7. Un detalle que despertó nuestro interés durante la iluminación del dolmen de Cubillejo es la posición en la pared oriental del corredor de la única losa que presenta grabados, coincidiendo en ello con otro ortostato singular, adornado con unas curiosas ondas, de Las Arnillas. Sin duda, la posición de ambos bloques dentro del megalito es deliberada y obedece a saberse de antemano que el rayo de sol, en el inexorable desplazamiento del astro hacia el oeste, acabará su recorrido en dicho punto.

El simbolismo de los grabados en Cubillejo, con dos cuadrúpedos y una rama, se nos escapa aunque no haya que olvidar la existencia junto a ellos de un círculo al que se ha identificado con el sol (Ledo-Fernández, 2016). Pero más inquietantes, pese a no ser antrópica su factura, son las ondas o rizaduras de Las Arnillas. El efecto de la iluminación en ellas es muy similar al que producen en igual circunstancia las lajas decoradas con agobiantes motivos geométricos de la cámara y del corredor del dolmen bretón de Gavrinis o de los exteriores de los megalitos irlandeses de Knowth y New Grange, los cuales recrean, en opinión de muchos estudiosos (Bradley, 1989; Guerra-Doce, 2006), visiones entópticas producidas en estados alterados de conciencia. Aunque las "rizaduras" de las losas de Las Arnillas sean de origen natural, simples ripplemar$k s$, se localizan dentro de la construcción en el sitio preciso para que en la fecha crítica la iluminación solar produzca el efecto deseado, lo que habla bien a las claras de la intencionalidad de la elección de este bloque y, acaso, de la posibilidad de que los constructores lo incorporaran al sepulcro creyéndolo erróneamente resto de algún monumento previo, esto es en un intento de aprovechar, como sucede con las célebres estelas del dolmen de Soto (Balbín y Bueno, 1996), cierta sacralidad remanente (Delibes de Castro y Moreno-Gallo, 2000). En todo caso, atribuimos tanto a los grabados de Cubillejo como a estas curiosas marcas naturales de Las Arnillas un incuestionable protagonismo en las ceremonias del sol durante el solsticio de invierno y vemos en ello un buen motivo para apoyar a quienes defienden que los corredores fueron algo más que meros dromoi para acceder a los sepulcros; que fueron también espacios sagrados en los que se veneraba a los ancestros por medio de rituales de paso en los que los oficiantes -en nuestro caso deberíamos pensar que al comienzo del invierno- actuarían en estado de trance (Guerra-Doce, 2006). ¿Tal vez en Las Arnillas guardaba relación con dichas celebraciones el enigmático "nido de cráneos" que se documentó a mitad del corredor, justo al pie de las piedras grabadas (Delibes de Castro et al. 1986)?

5.8. Por último, el estudio arqueoastronómico vendría a confirmar lo que hasta ahora era solo sospecha: que las comunidades megalíticas de Sedano y La Lora residían durante el invierno en la zona, esto es que no eran pastores trasterminantes venidos de fuera en verano para, como ocurría por estas mismas fechas en las cumbres cantábricas, aprovechar los pastos de los páramos y marchar de nuevo con la llegada de los fríos. En realidad el estudio polínico del paleosuelo sobre el que se asienta El Moreco ya había revelado indicios de cultivo de cereales, hecho que en un régimen agrícola tradicional de ciclo largo, con siembra a favor de las lluvias del otoño, obligaba a los campesinos a permanecer todo el año orilla de sus campos. Pero el estudio arqueoastronómico permite ir más allá: demuestra que aquellas personas disponían ya de un calendario y eran perfectos conocedores de la duración y del comportamiento de las estaciones. Dominaban y controlaban, en suma, el cómputo del tiempo, algo sin lo cual hubiera sido imposible el desarrollo de la vida campesina (Criado, 1989).

\section{CONCLUSIONES}

1.- El presente trabajo es un paso más en el intento de profundizar en el significado y circunstancias culturales en las que se construyeron los sepulcros de corredor neolíticos del noreste de la Submeseta Norte española. Del estudio combinado del rumbo de los ejes de los megalitos y de las características topográficas del terreno circundante se deduce una orientación sistemática a la salida del sol en el solsticio de invierno y, asimismo, que en ciertos casos la orografía obligó a pequeñas correcciones del eje del corredor. Pero la atención se ha focalizado, sobre todo, en observar sobre el terreno los efectos de la luz del sol naciente en varios de tales dólmenes, hecho que a la postre demuestra que las orientaciones fueron minuciosamente calculadas para propiciar que, unos pocos días en torno al comienzo del invierno, los rayos solares se adentraran por el pasillo e iluminaran el interior de los sepulcros.

2.- De lo deliberado de las orientaciones hablan también otros detalles, como la invariable localización de las manifestaciones de arte megalítico en puntos críticos -en lo que a iluminación se refiere- del interior de los monumentos. Demasiada casualidad que, durante el soslticio de invierno, el ortostato de las pinturas de la cámara de El Moreco sea el primero en recibir los rayos del sol naciente o que los grabados de Cubillejo de Lara y Las Arnillas se sitúen justo en aquellas losas de la pared oriental del corredor en las que, por esas mismas fechas, finaliza el recorrido de la luz por el interior del sepulcro.

3.- Obviamente, planificar un escenario luminoso de tal complejidad exige, además de conocer la mecánica 
celeste, una precisión arquitectónica considerable, lo que apunta a que la responsabilidad de la construcción de los dólmenes, aun siendo una empresa colectiva, debió recaer sobre los hombros de un "especialista", una suerte de astrónomo-geómetra. El proyectista hubo de enfrentarse a la dificultad de no disponer de referencias para orientar el corredor más que en los días críticos del solsticio de invierno, hecho que invita a pensar que la traza y construcción de los pasillos también tuvo lugar, simbólicamente, en dichas fechas. Y tal vez haya que relacionar con esa misma dificultad la pequeña falta de concordancia en la orientación de los ejes de cámara y corredor de algunos dólmenes -La Cabaña o El Moreco- pues podría ser que sólo el pasillo se construyera durante el solsticio invernal, como postrer complemento de una cámara construida previamente.

4.- Aunque hayamos dado por supuesto que la orientación del corredor fue motivada por fenómenos asociados al sol, no es descartable que la luna también jugara un papel importante. Para la zona de estudio, el azimut aproximado del orto de la luna en fase llena durante el solsticio de verano $\left(\sim 132^{\circ}\right)$ es muy próximo al azimut del orto solar del solsticio de invierno $\left(\sim 121^{\circ}\right)$, por lo que ambos fenómenos pudieron haberse tenido en cuenta. En todo caso, el posible uso conjunto de los ortos y ocasos de los solsticios de verano e invierno tanto de la luna como del sol, aún por contrastar, resultaría decisivo para pensar que nuestros antepasados disponían ya de un sofisticado calendario.

5.- En resumen, el análisis de la iluminación solar en nuestros mausoleos apunta con fuerza a que en ellos se contemplaba y celebraba cada año, a comienzos del invierno, el espectáculo de la luz. Un fenómeno sobresaliente que convertía aquellos días en fechas sagradas, propicias también para el desarrollo de otras actividades ceremoniales de hondo significado para la comunidad, tales como el ordenamiento y la manipulación de los osarios del interior de los sepulcros.

\section{BIBLIOGRAFÍA}

Armendáriz, Á., 1996. Sobre la orientación de ciertos sepulcros megalíticos de corredor del País Vasco Meridional. I Congrés del Neolític a la Península Ibérica. Gavà-Bellaterra. Rubricatum 2, 475-480. Museu de Gavà. Barcelona.

Basconcillos-Arce, J., Delibes de Castro, G., Fernández Manzano, J., Herrán Martínez, J. I., Moreno Gallo, M.Á., 2011. Indicios de explotación en época megalítica del criadero cuprífero de Huidobro (Burgos). In: Mata-Perelló, J.M., Torró, L., Fuentes, M.N. (Eds.), Actas del V Congreso internacional sobre minería y metalurgia históricas en el suroeste europeo, 131-142. SEDPGYM, Madrid.

Belmonte J.A., 1997. Mediterranean Archaeoastronomy and Archaeotopography: Two examples of dolmenic necropolises at the Jordan Valley. Archaeoastronomy Sup. J.H.A. 22, 37-43.

Belmonte, J.A. (Coord.), Antequera, L., Aparicio, A., Belmonte J. A., Esteban, C., Hoskin, M., Rebullida, A., 2000. Arqueoastronomía hispánica. Prácticas astronómicas en la Prehistoria de la Península Ibérica y los archipiélagos balear y canario. Equipo Sirius, Madrid.

Belmonte, J.A., González-García, A.C., 2012. The "genetic" analysis of Iberian dolmens: a test of the idea in the central Pyrenees. Journal for the History of Astronomy 43, 227-32.

Belmonte, J.A., González-García, A.C., Polcaro, A., 2013. On the orientation of megalithic monuments of theTransjordan Plateau: new clues for an astronomical interpretation. Journal for the History of Astronomy 44, 429-455.

Bonnefay, I., 1992. Diccionario de la mitología. III. De la Roma Arcaica a los sincretismos tardíos. Ed. Destino, Barcelona.

Bradley, R., 1989. Death and entrances: a contextual analysis of megalithic art. Current Anthropology 30(1), 68-75.

Bueno, P., Balbín, R., Barroso, R., 2008. Dioses y antepasados que salen de las piedras. Boletín del Instituto Andaluz del Patrimonio Histórico P.H. 67, 47-61.

Campillo, J., 1984. Hacia una sistematización del fenómeno dolménico en el NW. Burgalés. Kobie XIV, 143-170.

Cerdeño, M.L., Rodríguez Caderot, G., Moya, P.R., Ibarra, A., Herrero, S., 2006. Los estudios de arqueoastronomía en España: estado de la cuestión. Trabajos de Prehistoria 63, 13-34.

Chevalier, Y., 1999. Orientations of 935 dolmens of Southern France. Archaeoastronomy 24, 47-82.

Criado, F., 1989. Megalitos, espacio, pensamiento. Trabajos de Prehistoria 46, 75-89.

Cummings, V., Whittle, A., 2003. Tombs with a view: landscape, monuments and trees. Antiquity 77(296), 255-266.

De Balbín, R., Bueno, O., 1996. Soto, un ejemplo de arte megalítico del suroeste de la Península Ibérica. In: Moure Romanillo, A. (Ed.), El hombre fósil 80 años después: volumen conmemorativo del 50 aniversario de la muerte de Hugo Obermaier, 467-505. Universidad de Cantabria, Santander.

Delibes de Castro, G., 1995. Ritos funerarios, demografía y estructura social entre las comunidades neolíticas de la Submeseta Norte. In: Fábregas, R., Pérez, F., Fernández, C. (Eds.), Arqueoloxia da Morte. Arqueoloxia da Morte na Peninsula Ibérica desde as Orixes ata o Medievo, 63-94. Xinzo de Limia, Concello de Xinzo de Limia.

Delibes de Castro, G., 2000. Itinerario Arqueológico de los dólmenes de Sedano (Burgos). Trabajos de Prehistoria 57(2), 89-103.

Delibes de Castro, G., 2010. La investigación de las sepulturas colectivas monumentales del IV Milenio A.C. en la Submeseta Norte española. In: Fernández Eraso, J., Mujika-Alustiza J.A. (Eds.), Actas del Congreso Internacional sobre Megalitismo y otras manifestaciones funerarias contemporáneas en su contexto social, económico y cultural. Munibe. Suplemento 32, 12-56.

Delibes de Castro, G., Benet-Jordana, N., Pérez-Martín, R., Zapatero-Magdaleno, P., 1997. De la tumba dolménica como referente territorial, al poblado estable: Notas sobre el hábitat y las formas de vida de las comunidades megalíticas de la Submeseta Norte. In: Rodríguez Casal, A.A. (Ed.), O neolítico atlántico e as orixes do megalitismo, 779-808. Universidad de Santiago de Compostela.

Delibes de Castro, G., Moreno-Gallo, M., 2000. El dolmen de la Molina, una remembranza del padre Ibero 80 años después: Valredonda, escenario megalítico virtual. Boletín de la Institución Fernán González 78(220), 61-76. 
Delibes de Castro, G., Moreno-Gallo, M.Á., del Valle, A., 2011. Dólmenes de Sedano (Burgos) y criadero cuprífero de Huidobro: una relación todavía posible. In: Bueno, P., Gilman, A., Martín, C., Sánchez-Palencia, F.J. (Eds.), Arqueología, sociedad, territorio y paisaje: estudios sobre Prehistoria reciente, Protohistoria y transición al mundo romano en homenaje a $\mathrm{M}^{\mathrm{a}}$ Dolores Fernández-Posse, Bibliotheca Praehistorica Hispana XXVIII, 35-32. CSIC, Madrid.

Delibes de Castro, G., Rojo-Guerra, M.Á., 1988. En torno al origen del foco megalítico del oriente de la Meseta: de nuevo sobre el sepulcro de Cubillejo de Lara. Boletín del Seminario de Arte y Arqueología LIV, 5-23.

Delibes de Castro, G., Rojo-Guerra, M.Á., 1989. Pintura esquemática en el sepulcro de corredor burgalés de "El Moreco", Huidobro. Arqueología GEAP 20, 49-55.

Delibes de Castro, G., Rojo-Guerra, M.Á., 1997. C-14 y secuencia megalítica en La Lora burgalesa: acotaciones a la problemática de las dataciones absolutas referentes a yacimientos dolménicos. In: Rodríguez-Casal, A.A. (Ed.), O neolítico atlántico e as orixes do megalitismo, 391-414. Universidad de Santiago de Compostela.

Delibes de Castro, G., Rojo-Guerra, M.Á., 2002. Reflexiones sobre el trasfondo cultural del polimorfismo megalítico en la Lora burgalesa. Archivo Español de Arqueología 75, 21-35.

Delibes de Castro, G., Rojo-Guerra, M.Á., Represa-Bermejo, J.I., 1993. Dólmenes de La Lora, Burgos. Junta de Castilla y León, Valladolid.

Delibes de Castro, G., Rojo-Guerra, M.Á., Sanz-Mínguez, C., 1986. Dólmenes de Sedano. II. El sepulcro de corredor de Las Arnillas (Moradillo de Sedano, Burgos). Noticiario Arqueológico Hispano 27, 7-41. Ministerio de Cultura, Madrid.

Delibes de Castro, G., Santonja-Gómez, M., 1986. El fenómeno megalítico en la provincia de Salamanca. Diputación Provincial de Salamanca.

Font-Cot, J.O., 2005. La orientación de los megalitos: historia de las investigaciones en Cataluña (1894-2005). Mayurca 30, 225-244.

Gil-Merino, R., Moreno-Gallo, M.A., Delibes de Castro, G., González-García, A.C., 2009. Interdisciplinary Approach to Megalithic Tombs in Northern Iberia. Cosmology Across Cultures. ASP Conference Series 409, 349-353. Astronomical Society of the Pacific

Gómez, A., Hoskin, M., 2000. Studies in Iberian Archaeoastronomy (7): orientations of megalithic tombs of Huelva. Archaeoastronomy 25, 41-50.

González-García, A.C., 2009. Análisis estadístico de las orientaciones de los megalitos de la Península Ibérica. Complutum 20(2), 177-186

González-García, A.C., Kolev, D., Belmonte J.A., Koleva V., Tsonev. L., 2009. On the orientation of Thracian dolmens. Archaeoastronomy 22, 19-31.

González-García, A.C., Costa-Ferrer, L., 2006. Orientation of TRB-West megalithic monuments. Journal for the History of Astronomy 37, 417-427.

González-García, A.C., Costa-Ferrer L., 2007. Orientation of megalithic monuments in Germany and the Netherlands. Mediterranean Archaeology and Archaeometry 6(3), 201-208.

Guerra-Doce, E., 2006. Las drogas en la Prehistoria. Evidencias arqueológicas del consumo de sustancias psicoactivas en Europa. Bellaterra Arqueología, Barcelona.
Hoskin, M., 1997. Tombs, temples and orientations. In: Rodríguez-Casal, A.A. (Ed.), O neolítico atlántico e as orixes do megalitismo, 93-100. Universidad de Santiago de Compostela.

Hoskin, M., 1998. Studies in Iberian Archaeoastronomy: Orientation of Megalithic tombs of Northern and Western Iberia. Archaeoastronomy 23, 39-87.

Hoskin, M., 2001. Tombs, Temples and their orientations: a new perspective on Mediterranean Prehistory. Ocarina Books, Bognor Regis.

Hoskin, M., 2008. El estudio científico de los megalitos (3). La arqueoastronomía. Boletín del Instituto Andaluz del Patrimonio Histórico P.H. 67, 84-91.

Hoskin, M., 2009. Orientations of dolmens of Western Europe. Complutum 20 (2), 165-175

Hoskin, M., Allan, E., 1995. The orientations of Mediterranean tombs and sanctuaries. In: Ritual, Rites and Religion I, 38-67. BAR 611. Oxford

Hoskin, M., Allan, E., Gralewski, R.E., 1994. Studies in Iberian Archaeoastronomy (1): Orientations of the Megalithic Sepulchres of Almeria, Granada and Malaga. Archaeoastronomy 19, 55-82

Hoskin, M., Allan, E., Gralewski, R.E., 1995. Studies in Iberian Archaeoastronomy (2): Orientations of theTholos tombs of Almería. Archaeoastronomy 20, 29-39.

Hoskin M., Belmonte J.A., 1998. Studies in Iberian Archaeoastronomy (5): Orientations of megalithic tombs of Northern and Western Iberia. Section K: Granite tombs near Valencia de Alcántara, Cáceres. Archaeoastronomy Supl. J.H.A. 23, S70-S73.

Hoskin, M., Calado, M., 1998. Orientations of Iberian Tombs: Central Alentejo Region of Portugal. Archaeoastronomy 23, 77-82.

Hoskin, M., Higginbottom, G., 2002. Orientations of dolmens of West-Central France, Archaeoastronomy 27, 51-62.

Hoskin, M., Palomo, A., 1998a. Galicia. Studies in Iberian Archaeastronomy: Orientations of Megalithic Tombs of Northern and Western Iberia. Archaeoastronomy 23, 53-57.

Hoskin, M., Palomo, T., 1998b. Studies in Iberian Archaeoastronomy (4): The orientations of the Megalithic tombs of eastern Catalunya. Archaeoastronomy 29, 63-79.

Hoskin, M., Sauch, C., 1999. Studies in Iberian Archaeoastronomy (6): Orientations of megalithic tombs of Badajoz and neighbouring Portugal. Archaeoastronomy 24, 35-40.

Hoskin, M., Zedda, M., 1997. Orientation of Sardinian Dolmens. Archaeoastronomy 22, 1-16.

Hubert, H., Mauss, M., 1899. De la nature et la function du sacrifice. L'Année Sociologique 2, 29-138.

lund, R., 2002. Orientations of dolmens North of the Eastern Pyrenees. Archaeoastronomy 27, 21-28.

Jungmann, J.A., 1962. La liturgie des premiers siecles jusqu'a l'époque de Gregoire le Grand. Col. Lex Orandi 33, Paris.

Ledo-Fernández, F., 2016. Rescate documental de petroglifos y reconstrucción 3D del corredor dolménico de Cubillejo de Lara, Burgos. Virtual Archaeology Review, 7(14), 43-52.

López-Plaza, S., Alonso-Romero, F., Cornide-Castro, M., Álvarez-Santos, A., 1992. Aplicación de la astronomía al estudio de la orientación de sepulcros megalíticos de corredor en la zona noroccidental de la Península Ibérica. Zephyrus XLIVXLV, 183-192. 
López-Plaza, S., Senna, J.C., Hoskin, M., 1997. Revisión de las orientaciones de los sepulcros megalíticos de Salamanca. In: Jaschek, C., Atrio-Barandela, F. (Eds.), Actas del IV Congreso de la SEAC ("Astronomía en la Cultura"). Universidad de Salamanca.

Maluquer de Motes, J., 1973. En torno a la cultura megalítica de la Rioja alavesa. Estudios de Arqueología Alavesa 6, 83-101.

Martín-Asín, F., 1990. Astronomía. Ed. Autor-Editor. Madrid.

Masset, C., 1993. Les dolmens. Societés néolithiques et pratiques funeraires. Les sepultures collectives d'Europe occidentale. Errance, Paris.

Meeus, J., 1999. Astronomical Algorithms (2nd Ed.). Willmann-Bell, Inc. Virginia, USA.

Michell, J., 2002. Introducción a la Astroarqueología. Oberon-Grupo Anaya.

Moreno-Gallo, M.Á., 2005. 1954-2004: medio siglo de megalitismo en la provincia de Burgos. Boletín de la Institución Fernán González 230, 79-114.

Moreno-Gallo, M.Á., Delibes de Castro, G., López-Sáez, J.A. Manzano, S., Villalobos-García, R., Fraile-Vicente, A., Basconcillos-Arce, J., 2012. Nuevos datos sobre una alineación de menhires en el norte de Burgos: el yacimiento de Las Atalayas en Avellanosa del Páramo (Burgos). Sautuola 16-17, 71-93.

O’Kelly, M. J., 1982. Newgrange. Archaeology, art and legend. Thames and Hudson, London.

O’Reilly, J.P., 1893-1896. On the orientation of certain dolmens recently discovered in Catalonia. Proceedings of the Royal Irish Academy 3rd series III, 573-579.

Osaba, B., Abásolo, J. A., Uríbarri, J. L., Liz, C., 1971a. El dolmen de Porquera de Butrón en la provincia de Burgos. Noticiario Arqueológico Hispano XV, 75-108.

Osaba, B., Abásolo, J. A., Uríbarri, J. L., Liz, C., 1971b. El dolmen de Cubillejo de Lara de Los Infantes (Burgos). Noticiario Arqueológico Hispano XV, 109-123.

Oliveira, C., Rocha, L., da Silva, C. M., 2007. Megalitismo funerário no Alentejo Central. Arquitectura e orientaçoes: o estado da questao em Montemor-o-Novo. Revista Portuguesa de Arqueología 10(2), 35-74.

Patrick, J., 1974. Midwinter sunrise at Newgrange. Nature 249, 517-519.

Prendergast, F., 2012. The Neolithic monument of Newgrange in Ireland: a cosmic womb? In: Meaden G.T. (Ed.), Archaeology of Mother Earth Sites and Sanctuaries through the Ages. Rethinking symbols and images, art and artefacts from history and prehistory, 57-64. Archaeopress, Oxford. BAR 2389

Renfrew, C, 1976. Megaliths, territories and populations. In: Laet, S.J. (Ed.), Acculturation and continuity in Atlantic Europe: mainly during the Neolithic period and the Bronze Age: papers presented at the IV Atlantic Colloquium, 198-200. Brugge, DeTempel.

Robledo, C., 1954. Descubrimiento megalítico. Boletín de la Institución Fernán González XI, 297. Burgos.

Rojo-Guerra, M., 1993. El fenómeno megalítico en La Lora burgalesa. Tesis doctoral inédita. Universidad de Valladollid.

Ruggles, C., 2008. Arqueoastronomía. In: Renfrew, C., Bahn, P., (Eds), Arqueología. Conceptos clave, 30-35. Akal Universitaria, Madrid.
Sauzade, G., 2000. Orientation of the Provençal dolmens. Archaeoastronomy 25, 1-10.

Savory, H.N., 1974. The role of the upper Duero and Ebro basins in megalithic diffusion. Boletín del Seminario de Arte y Arqueología XL-XLI, 159-174.

Scarre, C., 2008. Nuevos enfoques para el estudios de los monumentos megalíticos de Europa Occidental. Boletín del Instituto Andaluz del Patrimonio Histórico P.H. 67, 24-33.

Sweatman, M. B., Tsikritsis, D., 2017. Decoding GöbekliTepe with archaeoastronomy: What does the fox say? Mediterranean Archaeology and Archaeometry 17(1), 233-250.

Tejedor-Rodríguez, C., 2014. Reconstruyendo "biografías megalíticas": algunos ejemplos de alteraciones estructurales en monumentos megalíticos del valle del Duero/Douro. In: Honrado-Castro, J., Brezmes-Escribano, M.Á., Tejeiro-Pizarro, A., Rodríguez-Monterrubio, O. (Eds.), II Jornadas de Jóvenes Investigadores del Valle del Duero. Del Neolítico a la Antigüedad Tardía, 67-86. Glyphos Publicaciones, Valladolid.

Villalobos-García, R., 2014. The megalithic tombs of the Spanish Northern Meseta. Material, political and ideological ties between the Neolithic people and their territory. Préhistoires Méditerranéennes, Colloque. Available from: http://pm.revues. org/1047 (Febrero 2018).

Villalobos-García, R., Delibes de Castro, G., Moreno-Gallo, M.Á., Basconcillos-Arce, J. 2014. The megalithic "Golden Crescent". An approach to one space in Northern Burgos (Spain) which hosted the adoption and evolution of megalithism. In: Debating Spatial Archaeology. Proceedings of the International Workshop on Landscape and Spatial Analysis in Archaeology, 131-141. Universidad de Cantabria.

Vivanco, J.J., 1981. Orientación y tipología de las cámaras de los dólmenes de montaña y valle. Estudios de Arqueología Alavesa 10, 67-144. 


\section{FOTOGRAFÍAS}
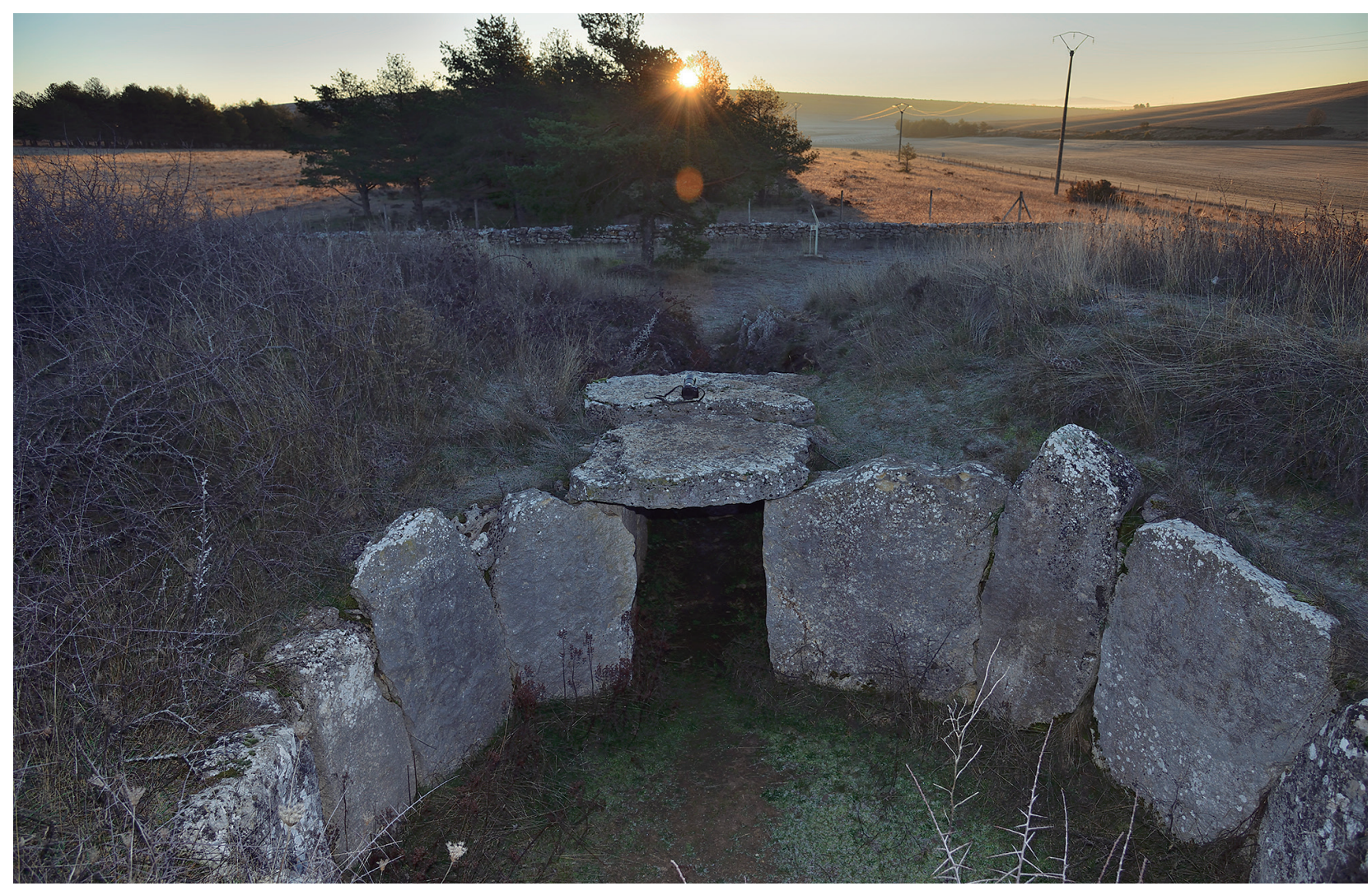

Foto/Photo 1. Dolmen de El Moreco: La salida del sol se ve obstaculizada por los pinos. Al fondo se observa la loma que también retrasa el fenómeno de la luz en el solsticio de invierno / El Moreco dolmen: sunrise light is stopped by a set of pines. Behind the pines there is a hill that delays the sunrise during the Winter solstice.

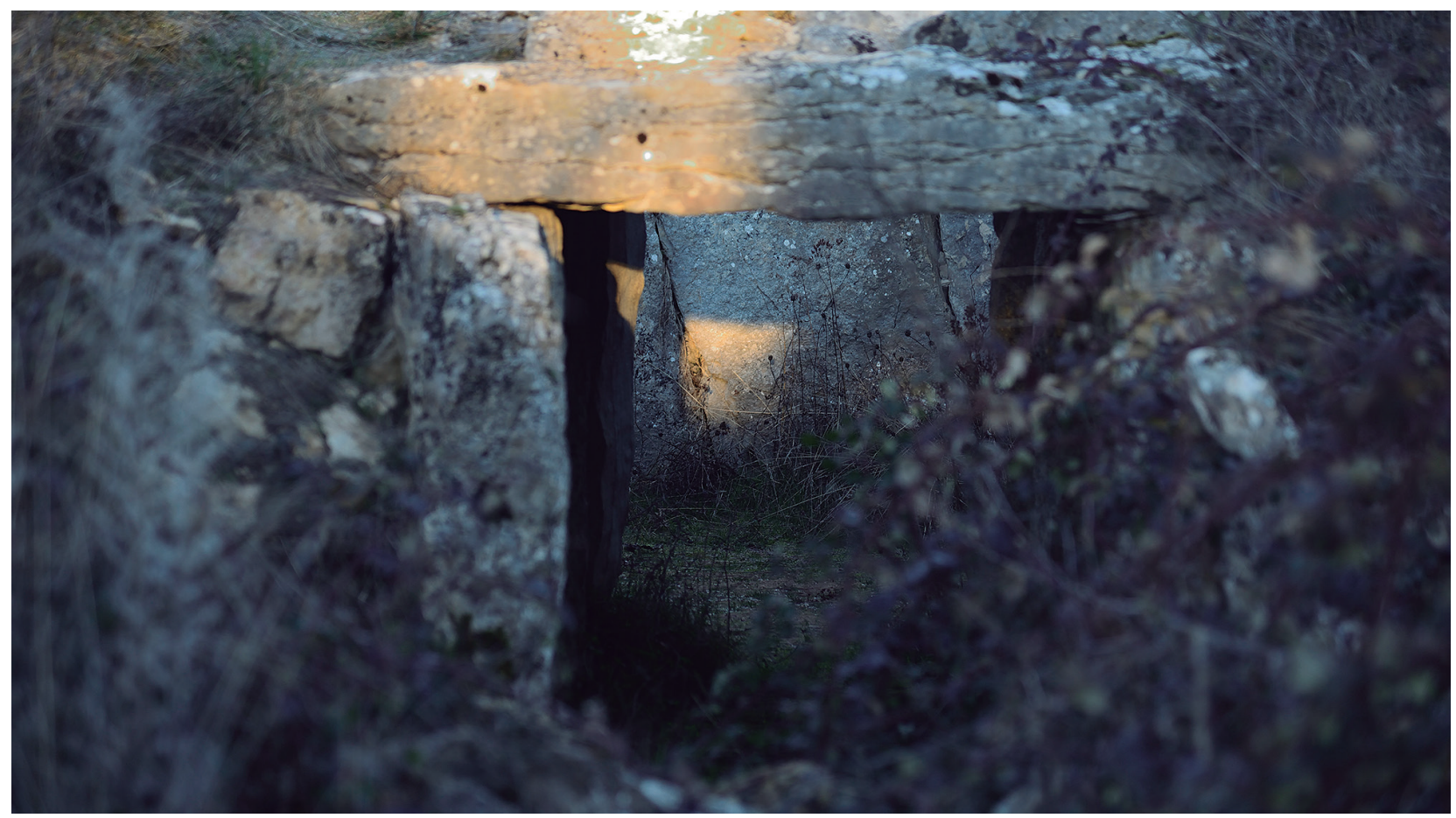

Foto/Photo 2. Momento en el que comienza ser iluminada la cámara de El Moreco a través del corredor / Beginning of the illumination of the chamber of El Moreco through the corridor. 


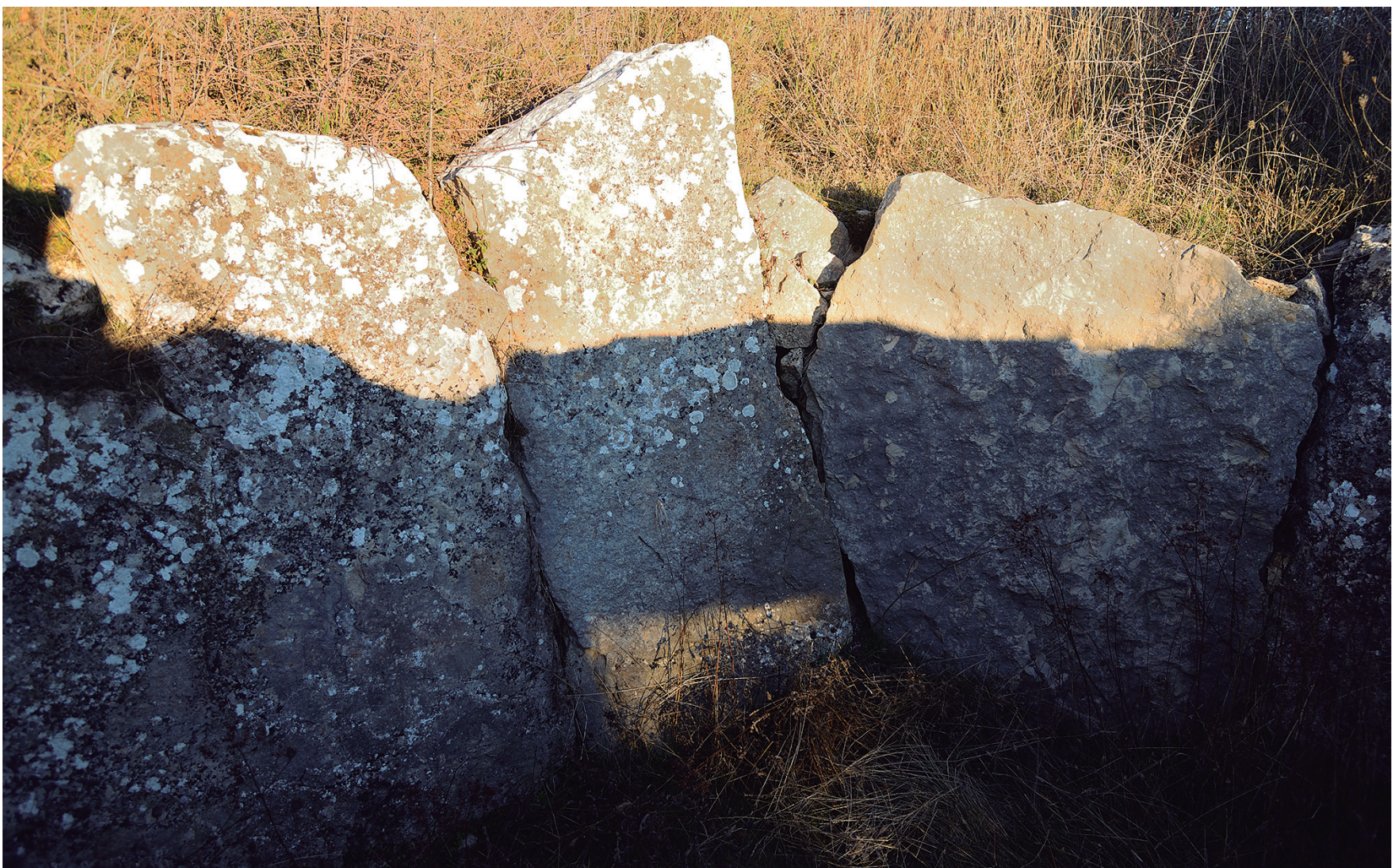

Foto/Photo 3. El sol no se proyecta en la losa central de la cámara de El Moreco, sino en una adyacente / The sun is not illuminating the central slab of the El Moreco chamber, but an adjacent one.

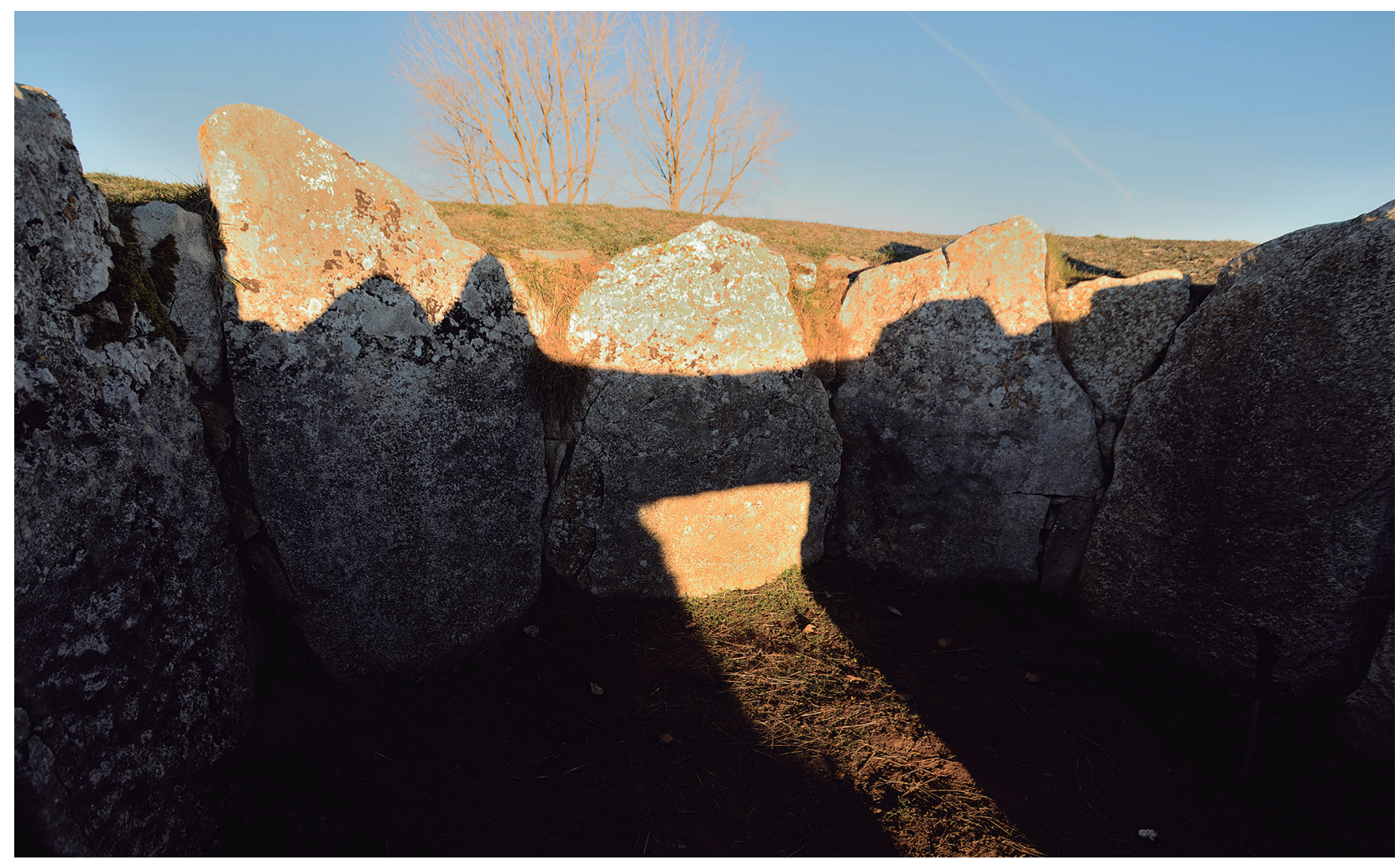

Foto/Photo 4. Proyección del sol naciente sobre la cámara de La Cabaña, en Sargentes de la Lora. Obsérvese la forma trapezoidal invertida / Projection of the sunrise light on the La Cabaña chamber, at Sargentes de La Lora. Observe the inverse trapezoidal shape. 


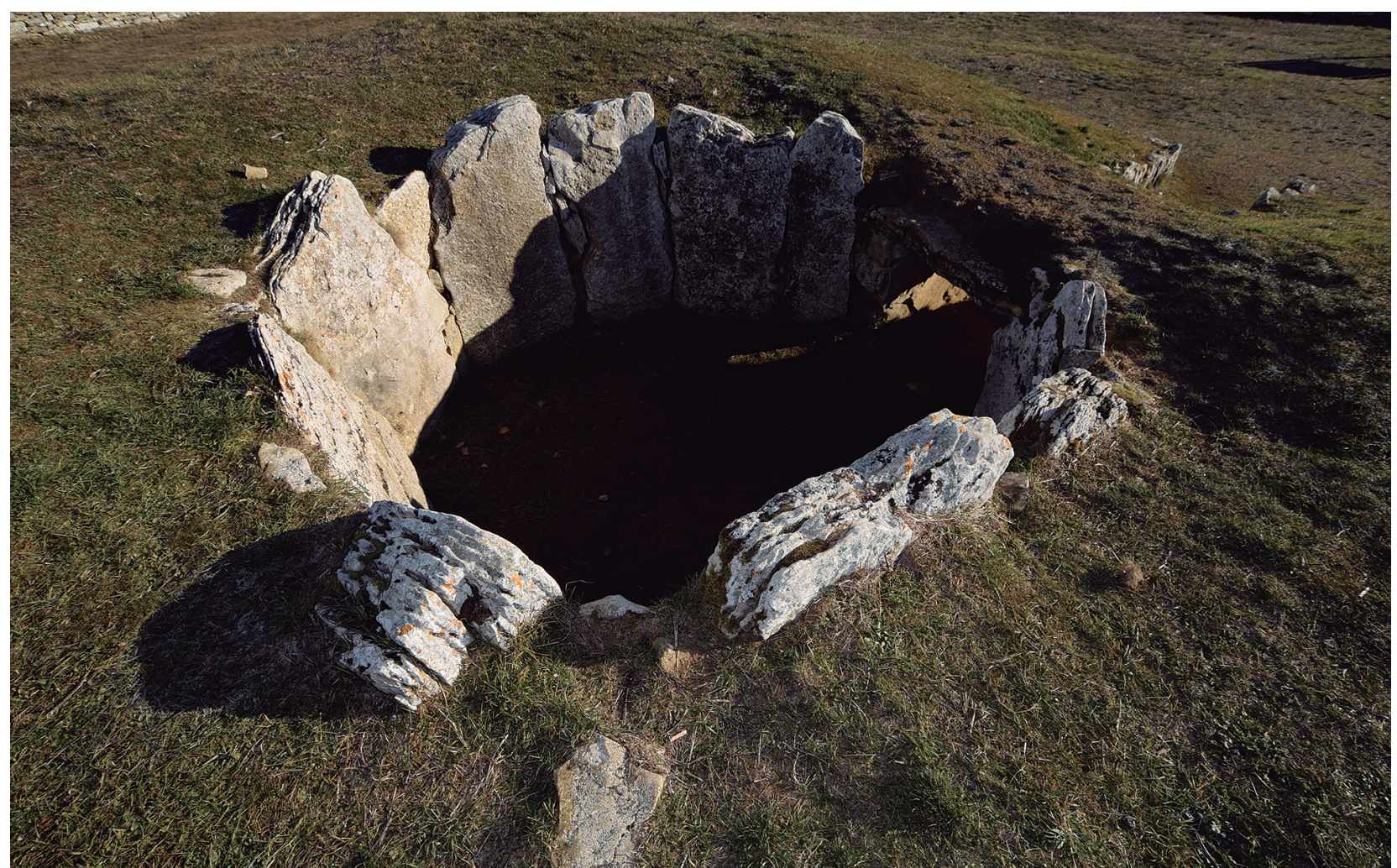

Foto/Photo 5. Dos horas después del comienzo del fenómeno, aún penetra el sol en la cámara de La Cabaña, en Sargentes de la Lora / Two hours after the beginning of the phenomenon, the sunlight still reaches the chamber of La Cabaña, at Sargentes de la Lora.

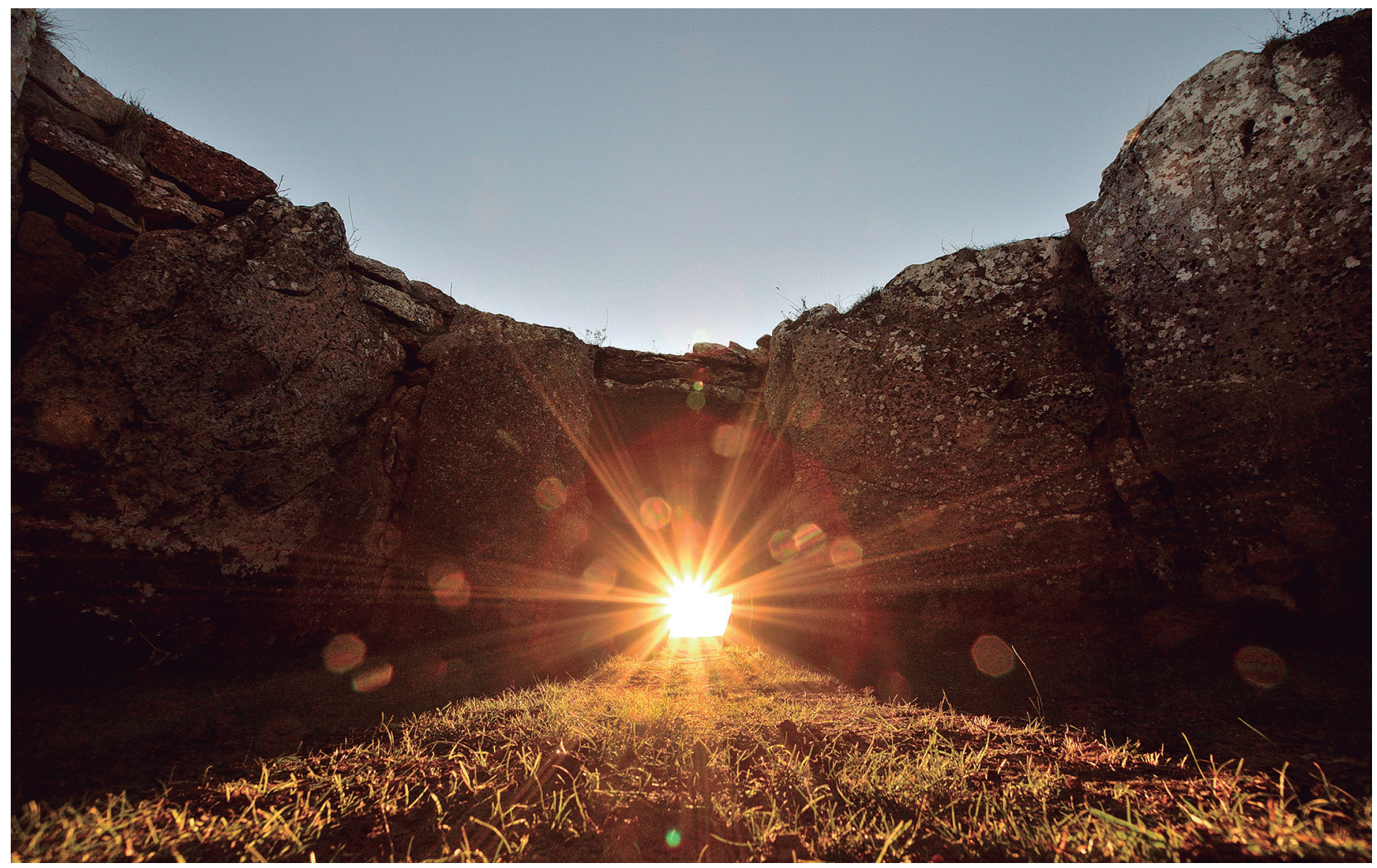

Foto/Photo 6. Entrada directa del sol en el dolmen de Las Arnillas / The sunlight directly entering inside the Las Arnillas dolmen. 


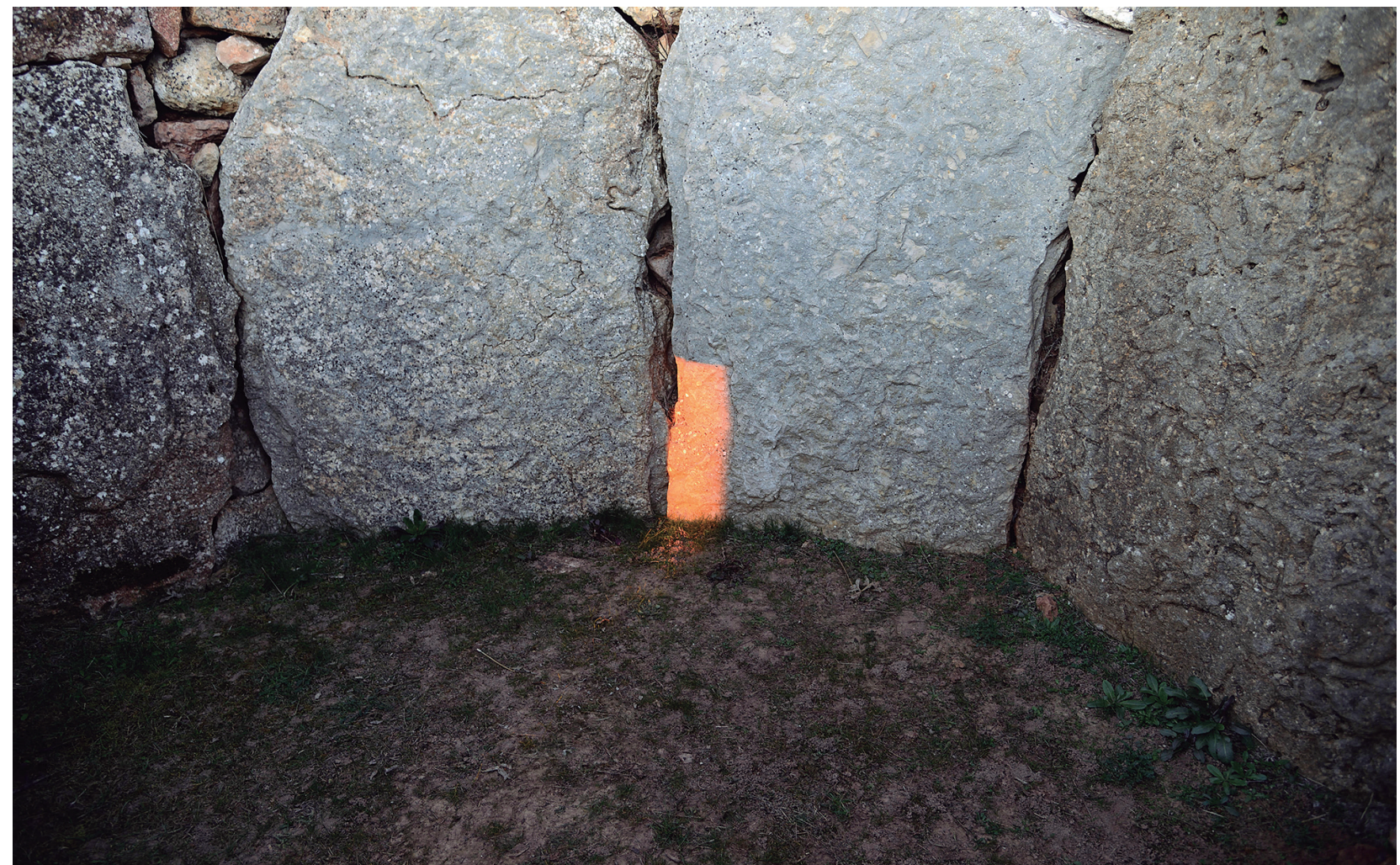

Foto/Photo 7. Comienzo de la iluminación de la losa de la cámara de Las Arnillas / The beginning of the illumination of the main slab in the chamber of Las Arnillas.

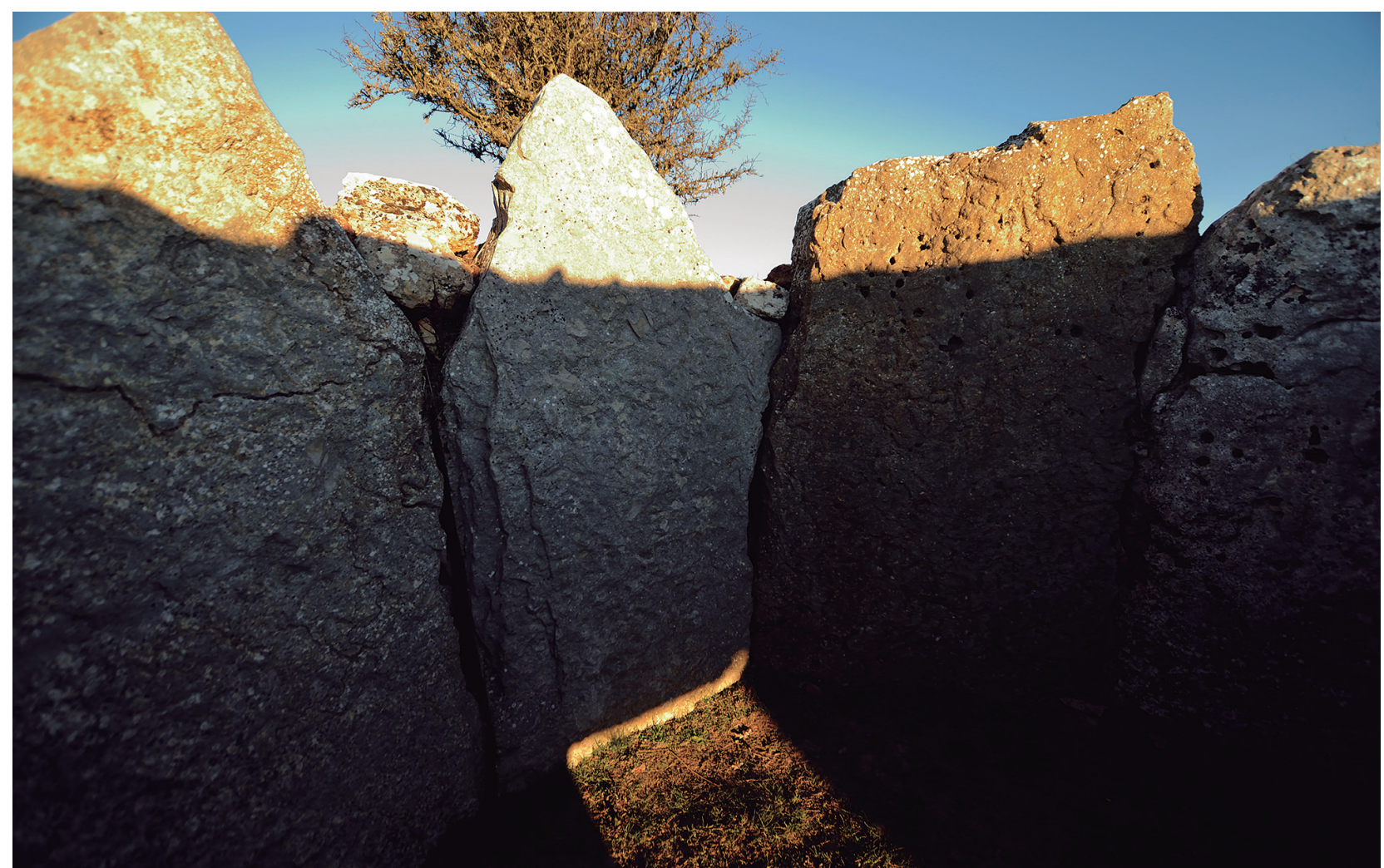

Foto/Photo 8. Posición final del sol en la losa de Las Arnillas / Final position of the sunlight on the main slab in Las Arnillas. 


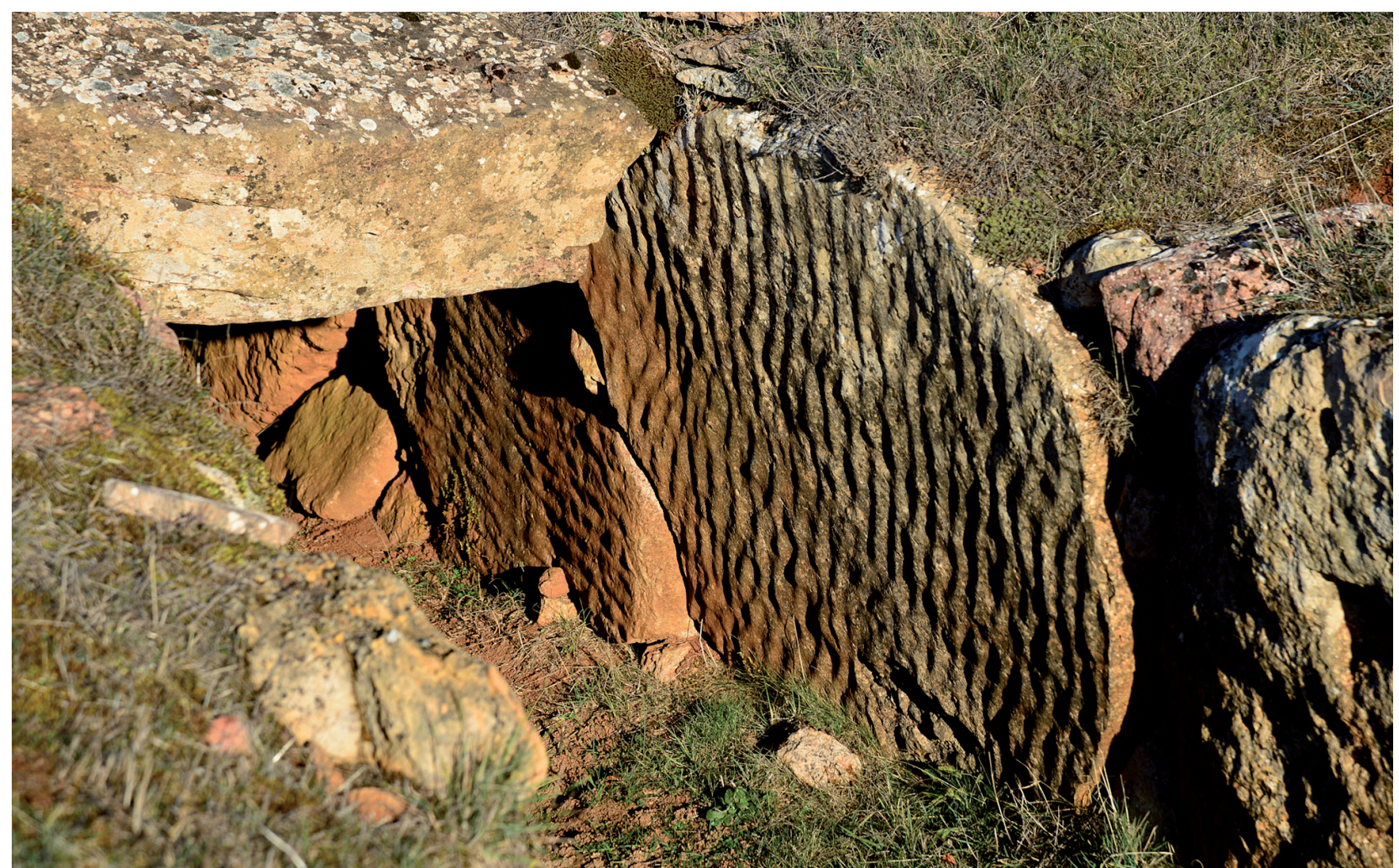

Foto/Photo 9. Proyección del sol en el amanecer del solsticio sobre las losas con rizaduras del corredor de Las Arnillas / Sunlight at dawn in the Winter solstice on the slabs with ripples forming the corridor of Las Arnillas.

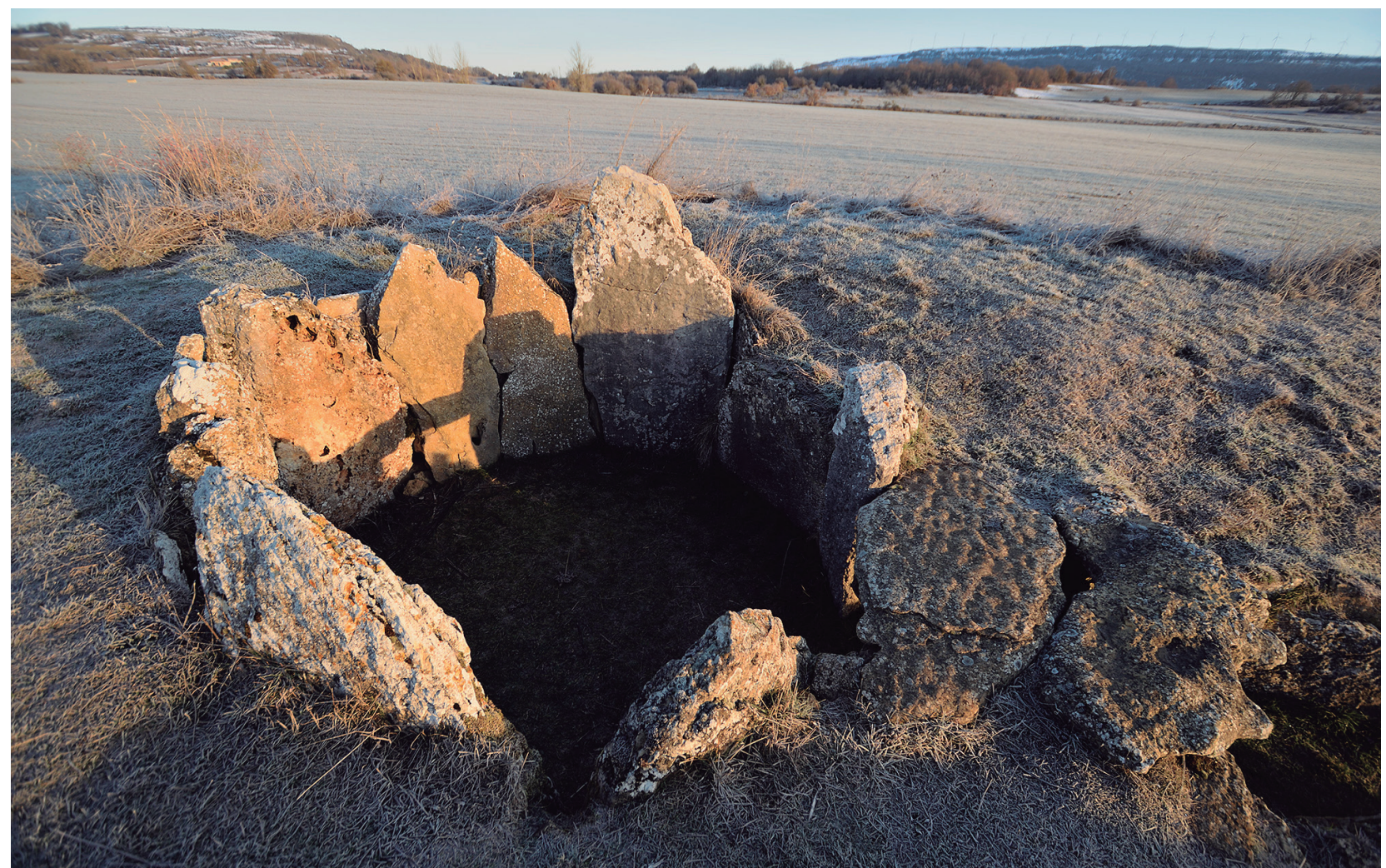

Foto/Photo 10. Proyección del sol sobre la cámara de La Cotorrita de Porquera del Butrón / Sunlight on the chamber of La Cotorrita at Porquera del Butrón. 


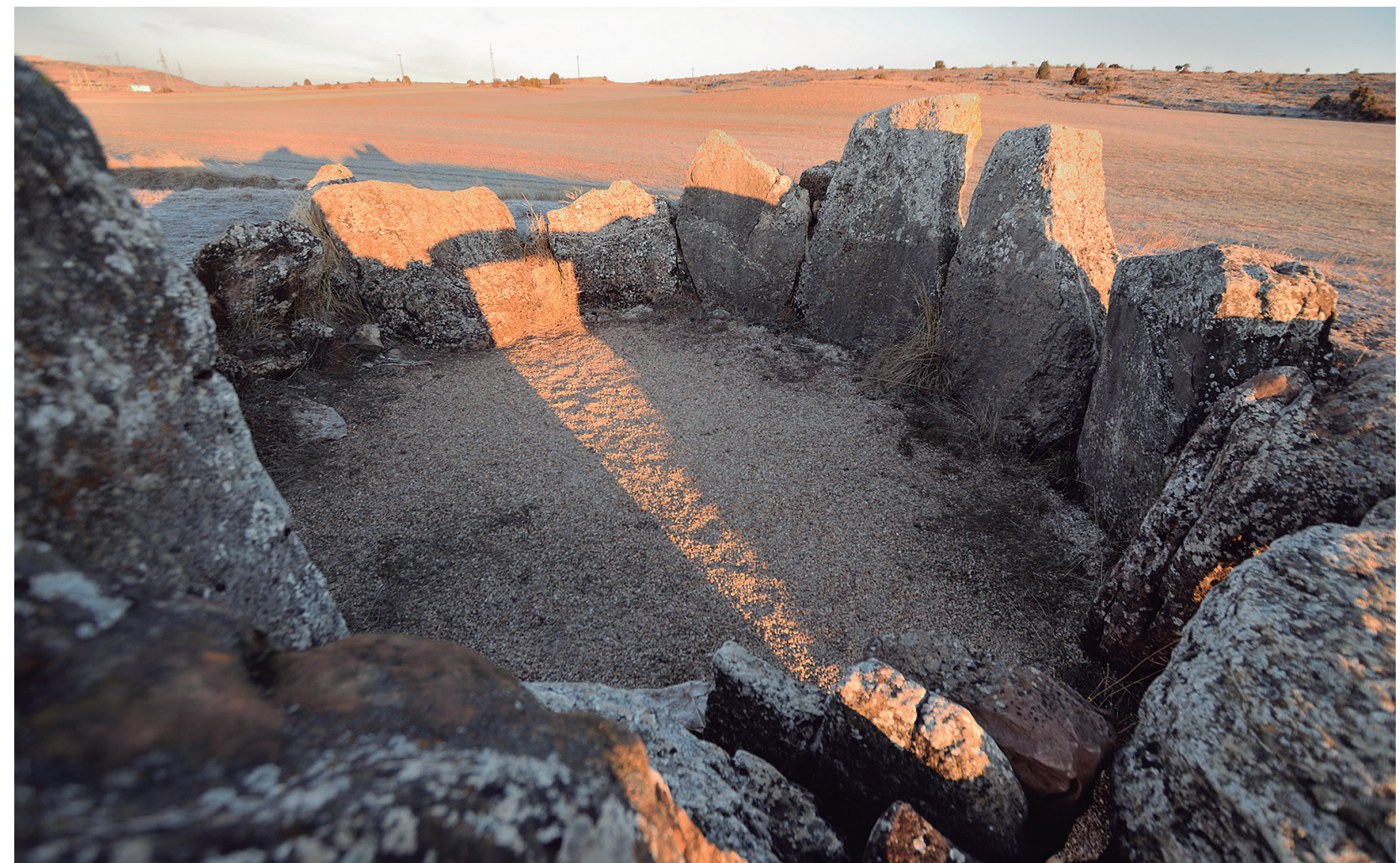

Foto/Photo 11. Proyección del sol en el dolmen de Cubillejo de Lara / Sunlight projection on the dolmen of Cubillejo de Lara.

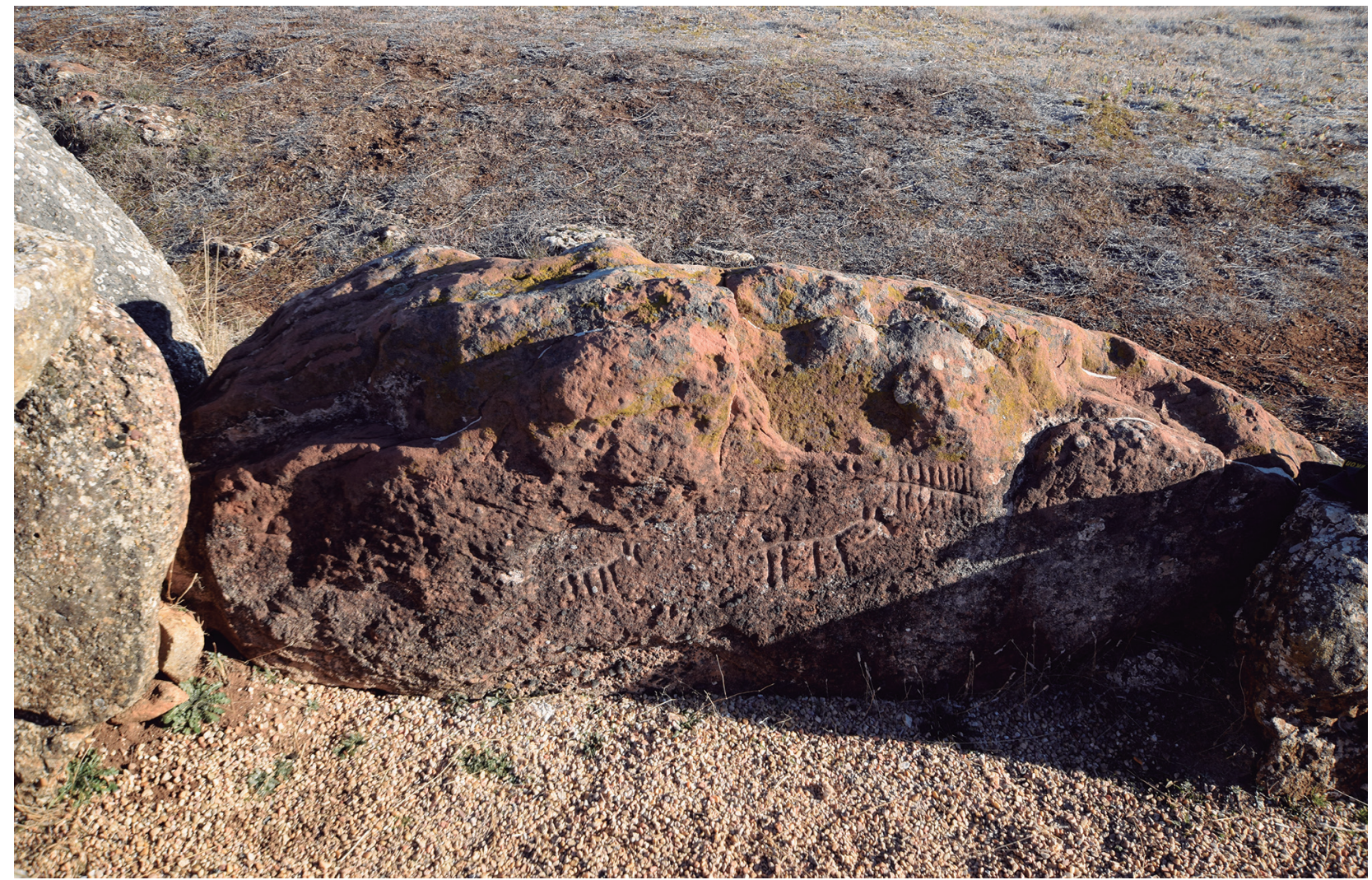

Foto/Photo 12. Grabados de la losa del corredor iluminados por el sol naciente / Engravings on the corridor slabs illuminated by the sunrise light. 
